\title{
Positive attitudes towards mathematics and science are mutually beneficial for student achievement: a latent profile analysis of TIMSS 2015
}

\author{
Nathan Berger $^{1}$ iD $\cdot$ Erin Mackenzie $^{1} \cdot$ Kathryn Holmes $^{1}$
}

Received: 31 May 2019 / Accepted: 28 January 2020 / Published online: 14 February 2020

(c) The Australian Association for Research in Education, Inc. 2020

\begin{abstract}
Australia has seen declining numbers of students choosing mathematics and science subjects in the senior secondary years, running counter to economic projections of an accelerating need for science and mathematics skills. Many students become less engaged with these subjects in the junior secondary years but attitudes such as selfconcept, utility value, and intrinsic value are important for subject selection decisions. We used latent profile analysis to examine the relationship between attitudes towards both subjects using data from 10,051 Australian Grade 8 students sampled by TIMSS 2015 and revealed six discrete groupings. While most students were at least attitudinally receptive to both subjects, there were many students who either resisted both or expressed a strong preference for one over another. Positive attitudes towards both subjects were mutually beneficial-better attitudes towards both were associated with higher achievement in each-but boys tended to be more positive towards both subjects and so benefitted from this relationship more than girls. Implications for educational research and teachers' practices are discussed.
\end{abstract}

Keywords Mathematics $\cdot$ Science $\cdot$ Attitudes $\cdot$ Latent profile analysis

Declining numbers of students electing to study mathematics and science is a significant issue as our society increasingly relies on workers in Science, Technology, Engineering, and Mathematics (STEM) fields (Kennedy et al. 2014). Many students,

Nathan Berger

n.berger@westernsydney.edu.au

Erin Mackenzie

e.mackenzie@westernsydney.edu.au

Kathryn Holmes

k.holmes@westernsydney.edu.au

1 Centre for Educational Research, Western Sydney University, Locked Bag 1797, Penrith, NSW 2751, Australia 
but particularly girls, become less engaged in mathematics and science in the early years of secondary school (Plenty and Heubeck 2013; Potvin, Hasni et al. 2018; Watt 2004). This is an important time to ensure all students remain engaged in these subjects. Empirical evidence shows that students' attitudes towards mathematics and science influence their academic achievement and decisions to continue studying these subjects (Britner and Pajares 2006; Dowker et al. 2016; Wang and Degol 2013). According to expectancy-value theory, the value placed on a task and the expected success in that task predict the extent of an individual's engagement with the task (Wigfield and Eccles 2000). While there are many different ways of measuring values and expectancies in science and mathematics, in this study we focus on three key constructs measured in the Trends in International Mathematics and Science Study (TIMSS) 2015. These attitudes are self-concept, intrinsic value, and utility value of mathematics and science. Self-concept aligns with the expectancy of success aspect of expectancy-value theory (Guo et al. 2015), while intrinsic and utility values reflect the interest and importance an individual places on mathematics and science (Wigfield and Eccles 2000).

The driving question for this study was whether differential expectancy-value profiles towards mathematics and science existed among Australian teenagers, and, if so, how these profiles were associated with gender and achievement in those subjects. In recent years, person-centred methods, which focus on the individual as the unit of analysis, have become increasingly popular for their ability to offer researchers and practitioners a more nuanced understanding of the motivational dynamics associated with particular student profiles (Watt et al. 2019). To this end, we used latent profile analysis to investigate the attitudinal profiles of Australian adolescents and how these profiles were associated with academic achievement in a standardised test of mathematics and science. The profiles we identified may serve as a useful heuristic for mathematics and science teachers to better understand the different types of students in their classrooms (Bae and DeBusk-Lane 2018).

Furthermore, where many previous studies have treated attitudes towards mathematics and science separately (e.g. Chouinard and Roy 2008; Guo et al. 2017; Stake 2006), our analysis jointly considered attitudes towards these subjects. While less common, research that has considered attitudes across subjects has made an important contribution to our understanding of how attitudes towards mathematics and science are related to achievement and subject selections (Chow and Salmela-Aro 2011). Given persistent gender differences in achievement and aspirations for science and mathematics, we considered the different ways that girls and boys regarded mathematics and science, and the association of these attitudes with achievement in these subjects.

\section{Student attitudes and participation in mathematics and science}

Expectancy-value theory states that engagement is predicted by the extent to which an individual values a task and his or her expected success in the task (Wigfield and Eccles 2000). Importantly, students' values and expected success in a subject predict their achievement in that subject (Wigfield et al. 2015). In a longitudinal 
study of adolescents from the United States, Wang (2012) found that task values were stronger predictors of engagement and choices to continue studying mathematics, while expectations of success and self-concept served as stronger predictors of academic achievement. In a comparative study of Australian, United States, and Canadian adolescents, Watt et al. (2012) reported that intrinsic value of mathematics was a key predictor of intentions to continue studying mathematics for Australian adolescents, while ability beliefs were stronger predictors in the United States and Canadian samples. Importance value (utility value) predicted girls' choices across the different context samples. Watt et al. (2012) interpreted this finding as indicative of a strong Australian desire for individual self-expression in academic life, relative to the other two countries, given the (at the time) lesser importance placed on standardised testing, which may promote more ability-focused beliefs in the United States and Canada.

In the following section, we explore the empirical evidence that links self-concept, intrinsic value, and utility value with science and mathematics participation, as well as gender differences in these relationships. While it is acknowledged that science consists of several domains (i.e. physics, chemistry, biology, and Earth and environmental science), many studies refer to science as a single subject. This is the case in the Australian TIMSS sample, reflecting the teaching of science as a single subject in Australian secondary schools until the senior years. In the following sections, we refer to previous studies that measure science as a single subject as "general science", and specify individual science domains when these have been studied separately.

\section{Ability beliefs}

Ability beliefs reflect the extent to which an individual believes they are competent in a subject (Wigfield and Eccles 2000). There are several ways to operationalise ability beliefs, including confidence, self-efficacy, and self-concept (Guo et al. 2017; Lee and Stankov 2018). The TIMSS 2015 scales labelled Students Confident in Mathematics/Science represent a measure of self-concept (Liou 2017; Michaelides et al. 2019; Stankov and Lee 2017), defined as "the extent to which students feel competent in the domain being asked" (Stankov 2013, p. 729). Self-concept is influenced by feedback received from others and individuals' evaluation of their performances (Bong et al. 2012).

Several meta-analyses have established that self-concept is positively related to academic achievement (e.g. Hattie 2008; Marsh and Martin 2011) and that this relationship is reciprocal (Marsh and Craven 2006). Further, in an analysis of TIMSS 2011 data from 26 countries, Liou (2017) found that self-concept in science was more strongly associated with science achievement in comparison to utility and intrinsic values in 20 of these countries (including Australia). Self-concept is also related to a range of other positive educational outcomes. For example, analysis of TIMSS 2007 data from 49 countries revealed that adolescents with higher levels of mathematics self-concept were more likely to report intentions to pursue a mathematics-related career, even when mathematics achievement was controlled for, and 
that self-concept was more predictive of mathematics career intentions than achievement in mathematics (Goldman and Penner 2016). Analysis of the Program for International Student Assessment (PISA) 2006 data of 54 countries also showed that science self-concept mediated the positive relationship between achievement and science career aspirations, reinforcing the critical role of self-concept in adolescents' career intentions (Nagengast and Marsh 2012).

The internal-external frame of reference model (I/E model) suggests that learners' self-concepts are influenced by comparing their abilities with those of peers (external) and their performance in other subjects (internal) (Marsh 1986). External comparisons with peers may lead students to over- or under-estimate their capabilities (Marsh et al. 2008), whereby students in a class with above-average classmates may have a lower self-concept in comparison to students in a class with belowaverage classmates. Learners can also evaluate their capabilities in a subject relative to other subjects, which can lead to higher self-concept in the stronger subject and lower self-concept in the weaker subject. These "dimensional comparisons" explain why mathematics and verbal self-concept tend to be uncorrelated, despite achievement in these areas being positively correlated (Marsh et al. 2015). The I/E model has been extended to examine the interaction of self-concepts in subjects that are more closely related, such as mathematics and science. In multiple English-speaking countries (including Australia), a contrast effect was reported between achievement and self-concept in mathematics and general science, whereby achievement in mathematics was negatively related to self-concept in science (Chiu 2008). However, a more recent German study found that when separate science subjects (biology, chemistry, physics) were considered, contrast effects existed between mathematics and biology, but assimilation effects (i.e. positive relationships between achievement and self-concept in different subjects) were detected between mathematics, physics, and chemistry (Jansen et al. 2015). It also appears that if a student perceives a large difference between the two subjects, he or she experiences greater self-concept differences (Helm et al. 2016). This suggests that students may vary in how their selfconcepts in mathematics and science are related.

Gender differences in adolescents' self-concept in mathematics are relatively common. For example, in most countries surveyed in TIMSS 2003 and 2007, boys were found to have greater self-concept in mathematics than girls (Goldman and Penner 2016; Wilkins 2004). These findings are mirrored in other studies that have measured adolescent gender differences in self-concept (Fredricks and Eccles 2002; Skaalvik and Skaalvik 2004). Furthermore, gender differences in mathematics selfconcept that exist in early secondary school have been found to persist throughout secondary school in Australian, US, and German adolescents (Nagy et al. 2010). Findings regarding gender differences in science self-concept are less consistent. In multi-national studies that have focused on gender differences in general science self-concept, some have found that adolescent boys report greater self-concept in science than girls (Sikora and Pokropek 2012; Wilkins 2004). However, other studies in specific national contexts, like the United States, have reported that there is no difference between the self-concept of boys and girls in general science (Louis and Mistelle 2012). These disparate findings may be due to the measurement of general science self-concept. In support of this, Jansen, Schroeders, and Lüdtke (2014) 
found that German male adolescents had higher self-concepts in physics and chemistry than girls, while there was no gender difference in biology self-concept when controlling for achievement.

While these variable-centred methods have made significant contributions to our understanding of gender differences in mathematics and science self-concepts, person-centred methods have also been adopted. For example, latent profile analysis recently has been used to identify distinct self-concept profiles across five subject domains (mathematics, physics, biology, reading, and English) in German adolescents (Sass and Kampa 2019). In that study, four self-concept profiles emerged: high mathematics-related self-concept, low overall self-concept, high verbal self-concept, and high overall self-concept. There were gender differences within these profiles, such that girls were overrepresented in the low overall self-concept and high verbal self-concept profiles, and underrepresented in the high mathematics-related selfconcept and high overall self-concept profiles (Sass and Kampa 2019). These findings reinforce the gender differences observed in variable-centred methods, but also suggest that person-centred methods can provide further insights into the complex ways that gender interacts with other variables to influence science and mathematics self-concept.

\section{Intrinsic value}

Intrinsic value towards a subject refers to the enjoyment and interest that an individual experiences while participating in that subject (Eccles 2005; Nagy et al. 2008). For Australian adolescents, intrinsically valuing mathematics (as measured by liking, interest, and enjoyment of mathematics) has predicted the continued study of mathematics in the senior years of secondary school (Watt et al. 2012). Multinational studies have similarly found that enjoyment of science is related to adolescents' intentions to continue studying science (Ainley and Ainley 2011a). Importantly, data from 57 countries have shown that enjoyment of science mediates the relationship between science content knowledge and intentions to continue studying science (Ainley and Ainley 2011b), which suggests that even high-achieving students may disengage from science if they do not experience positive affect when learning science. Indeed, adolescents with high self-concept in each of the science domains are less likely to aspire to a science-related career if their intrinsic value of the corresponding science domain is low (Guo et al. 2017).

Enjoyment of mathematics has been found to decrease during Grade 7 in Dutch adolescents (Ahmed et al. 2013) and from Grade 7 to Grade 8 in German adolescents (Frenzel et al. 2009). This may be in part due to declines in motivation and self-confidence during this period (Ahmed et al. 2013). This decline in intrinsic valuing of mathematics during the junior years of secondary school is also supported by a longer-term longitudinal study of Australian adolescents, with intrinsic value stabilising in the senior years (Watt 2004). These findings are concerning, given the importance of intrinsic value for continued engagement in mathematics and science (Ainley and Ainley 2011a; Watt et al. 2012). 
In comparison to self-concept, there is a less consistent gender difference in girls' and boys' intrinsic value of mathematics and science. Some studies have found that girls express lower levels of enjoyment of mathematics and general science than boys (Nagy et al. 2008; Riegle-Crumb et al. 2011). Others have found that this difference does not emerge in all countries, which implies that schooling systems and contexts influence students' intrinsic valuing of mathematics (Watt et al. 2012). In an Australian sample, girls' intrinsic valuing of mathematics was found to be lower than boys (Watt et al. 2012). There also appear to be gender differences in the relationships between intrinsic valuing of science and achievement. For example, DeBacker and Nelson (1999) found that intrinsic valuing of general science was related to greater academic achievement for boys, while this relationship was not significant for girls. In the same study, higher intrinsic valuing of science was related to greater application of effort for adolescent boys, and greater persistence for girls.

\section{Utility value}

A student's perceived value of mathematics or science reflects the extent to which a student views each subject as being useful, important, or having applications in other contexts. The perceived importance or usefulness of a task or subject is sometimes referred to as utility value (Watt 2004). Perceived support for mathematics from parents and teachers is an important predictor of utility value (Chouinard et al. 2007). While utility values did not predict achievement or engagement in mathematics after controlling for self-concept (Guo et al. 2016), utility values have been found to predict aspirations for mathematics-related professions for Australian female secondary school students (Watt et al. 2012). Similarly, adolescents who value general science are more likely to express the intention to continue to engage with learning science in the future and to experience enjoyment and interest when learning science (Ainley and Ainley 2011a). It is concerning that Australian adolescents' mathematics utility values have been found to decline during secondary school (Watt 2004).

Several studies have reported that there are no gender differences in adolescents' valuing of mathematics. For example, Jacobs, Lanza, Osgood, Eccles, and Wigfield (2002) reported that task values in mathematics were similar for boys and girls in the United States. Similarly, Watt (2004) found that girls and boys in Australian secondary schools did not have significantly different levels of mathematics utility value. This suggests that the importance of mathematics is communicated to boys and girls equally within these educational contexts (Watt 2004). In contrast, there is evidence to suggest that gender differences in utility values for science do exist. However, the nature of this difference varies by study. For example, Else-Quest et al. (2013) reported that adolescent girls valued general science more than boys in an ethnically diverse American sample. Conversely, George (2006) reported that girls held lower utility values for general science than boys in Grade 7, and that the increase in utility value that occurred during secondary school was smaller for girls. While it is possible that the importance of science is differentially communicated to male and female students in different contexts, this finding may also reflect a shift in how the importance of science is communicated to girls over time. 


\section{Joint consideration of attitudes towards mathematics and science}

Mathematics forms an integral part of most science disciplines and has been recognised as a gatekeeper to further science study and ultimately to science-related careers (Douglas and Attewell 2017; Shapka et al. 2006). It has been recognised over several decades that students' confidence and self-concept in mathematics can influence intention to study science-based courses after leaving school (Betz and Hackett 1983; Lin et al. 2018; Mau 2003; Sass and Kampa 2019). Specifically, for female students in Australia, perceived ability in mathematics has been found to predict intentions to pursue a career in mathematics, physics, chemistry, and biology (Watt et al. 2017). There is also evidence that girls are less confident in mathematics than boys even when their achievement is comparable, potentially discouraging them from a science career even if their interest is high (Sax et al. 2015).

It is therefore important to consider both mathematics and science in tandem, even if students are studying these subjects independently at school. The I/E model of self-concept supports the view that there are important relationships between self-concept in mathematics and science (Jansen et al. 2015), and that these relationships may be influenced by the extent to which a student views these subjects as similar (Helm et al. 2016). Further, students' intrinsic value (or lack of intrinsic value) in science might influence their intrinsic value in mathematics and vice versa. Understanding the interaction between students' perceptions of these subjects and their self-perceptions as learners in these subjects could lead to a more nuanced understanding of the dynamics at play in subject choice as students progress towards the senior years of schooling.

\section{Person-centred quantitative analyses}

There frequently is a need in quantitative social research to reduce large numbers of variables into smaller groupings (Schreiber and Pekarik 2014) to understand the underlying structure of the data (Eshghi et al. 2011). Groups may be "constructed composites derived directly from values that are found in the original variables, such as socioeconomic status" or "latent constructs derived indirectly from the original variables" (Schreiber and Pekarik 2014, p. 45). In the latter case, the relationships between the observed variables are analysed to arrive at unobserved categorical variables that allow the data to be segmented into exclusive subsets, called latent profiles (Haughton et al. 2009). In simple terms, a latent profile approach allows the data to 'speak for itself' rather than the researcher applying some a priori ideas about what the underlying structures in the data might be. That is, latent profile techniques can be characterised as a 'person-centred' rather than 'variable-centred' method of data analysis.

While the defining theoretical and methodological features of person-centred approaches have been debated (see Sterba and Bauer 2010), broad characteristics 
may be discerned (Michaelides et al. 2019). Person-centred or person-oriented methods focus on the relationships among individuals (Jung and Wickrama 2008). Techniques such as cluster and latent profile analysis are increasingly being used to understand individual response patterns and how individuals might be classified into distinct categories that are unobserved directly and are revealed a posteriori through analysis (Jung and Wikrama 2008). Studies that used personcentred methods have revealed groups of students with distinctive profiles that would have remained undetected in a variable-centred analysis (Michaelides et al. 2019).

There are several approaches to the identification of latent profiles. Traditional clustering techniques such as hierarchical cluster analysis and k-means cluster analysis are widely used in the social sciences, such as for market segmentation in marketing (Haughton et al. 2009). These methods typically divide data into groups by measuring the Euclidean distance between data points and seeking simultaneously to minimise within-group distances and maximise between-group distances (Kent et al. 2014; Schreiber and Pekarik 2014). By comparison, latent profile analysis (LPA) uses probabilistic mathematical modelling based on correlations between variables to identify likely groups and the placement of individuals within them (Kent et al. 2014).

Such person-centred methods have enabled a deeper investigation of substantive research questions in many disciplines (Nyland et al. 2007). In relation to education, Watt et al. (2019) used latent profile analysis to investigate how motivational expectancies and values predict aspirations for STEM careers in a sample of Australian adolescents. The profiles they first revealed using a person-centred method yielded theoretically and practically meaningful groupings which had different expectancies/ values and aspirations. Students in the study were "positively engaged" when they scored high on positive motivations and low on costs, "struggling ambitious" when they scored high on both positive motivations and costs, and "disengaged" when they had low scores on positive motivations but high scores on costs, in each subject area of mathematics and science (Watt et al. 2019). Watt et al. (2019) remarked that the person-centred method "allowed consideration of how motivational dimensions combined among different types of students to offer a nuanced understanding of the features and dynamics associated with particular profiles" (p. 7). In an applied discipline such as education, teachers and other practitioners may find more meaningful associations between the outcomes of educational research which has employed a person-centred approach and their everyday experiences with their students. The profiles resulting from a person-centred approach may serve as a useful heuristic for understanding student attitudes, thus enabling teachers to tailor their pedagogical approaches to the different types of students in the classroom (Bae and DeBuskLane 2018; Watt et al. 2019).

\section{Current study}

In this study, we use a person-centred method to investigate (i) how attitudes towards mathematics and science jointly manifest as discrete profiles in a sample of Australian teenagers, and (ii) how these profiles are associated with student gender and 
achievement in both mathematics and science. While this study is conventional in the sense that we use these findings to make suggestions for further research and discuss implications for practice in STEM education, we also aim to demonstrate the utility of person-centred methods in educational research and seek to provide useful suggestions for other researchers interested in pursuing these approaches.

\section{Method}

\section{Dataset and sample}

Data came from the 2015 edition of the Trends in International Mathematics and Science Study (TIMSS) administered by the International Association for the Evaluation of Educational Achievement (IEA). TIMSS 2015 was a standardised test that enables countries to monitor primary and secondary school students' knowledge of concepts and processes in mathematics and science, their attitudes towards those subjects, and the country's standing on these measures relative to other countries (Thomson et al. 2017). Internationally, over 580,000 students in Grade 4 and Grade 8 from 49 countries underwent the testing in 2015. In Australia, a representative sample of 6057 10-year-olds from 287 primary schools and 10,338 14-year-olds from 285 secondary schools participated in TIMSS. As discussed by Thomson et al. (2017), TIMSS used a two-stage stratified cluster sample design, which was intended to create a representative sample of each stratum. The first stage involved sampling schools stratified by jurisdiction, sector, geographic location, and socioeconomic status. The second stage involved taking a sample of one or two intact classes from the target age group in the sampled schools. Questionnaires and achievement tests were conducted in October and November 2014, which is towards the end of the school year in Australia. Statistical weightings were applied to enable the sampled students to represent the total population (Thomson et al. 2017). Data reported in this paper were from the Grade 8 sample of Australian students, not clustered by school but with sampling weights applied.

Students completed a paper-based attitudinal questionnaire and a mathematics/ science assessment booklet. As the large number of test items could not be reasonably completed within the allotted 90 minutes of testing time, the items were grouped into clusters and distributed through 14 test booklets so that each cluster appeared in more than one booklet (for a fuller description, see Thomson et al. 2017). Each student completed only one booklet. This complex procedure ensured all items were answered, albeit by a subsample of the total number of participating students. Consequently, individual achievement scores for mathematics and science contained a substantial amount of measurement error as each student only completed a subsample of items (Von Davier et al. 2009). To reflect this uncertainty, several imputed scores, called plausible values, were given for each individual on achievement variables (Laukaityte and Wiberg 2017). As plausible values were not individual scores, special care should be taken when working with large datasets which include them. We will return to this important consideration in the analysis section. 
According to Thomson et al. (2017), student achievement in mathematics and science was assessed by TIMSS in relation to a content domain (subject matter) and a cognitive domain (subject-relevant thinking processes). Once assessed, student achievement scores in mathematics and science were scaled using item response theory to range between 0 and 1000, with most scores being between 300 and 700 (Foy 2017). Higher scores indicated better achievement in the subject. However, it was important to understand the competencies associated with different scores and the IEA produced the TIMSS International Benchmarks that indicated students' knowledge, skills, and reasoning ability at different levels of the achievement scales. The benchmarks were created using a scale anchoring process described at length in Foy (2017). The IEA defined the international benchmark cut-offs in relation to the achievement scores as follows. The Low International Benchmark corresponded to achievement scores greater than 400, the Intermediate International Benchmark indicated scores greater than 475, the High International Benchmark corresponded to scores greater than 550, and the Advanced International Benchmark indicated scores greater than 625 (Foy 2017).

The first column of Table 1 shows sample characteristics. As might be expected from a representative sample of Grade 8 students, there were equal proportions of girls and boys in the sample. The largest proportion of students achieved the intermediate international benchmarks for mathematics (32\%) and science (33\%). The most frequently reported parental education level was a university qualification $(27 \%)$. While a substantial number $(38 \%)$ of students did not know how far their parents had gone in education, this does not appear to be unusual in studies of Australian teenagers (Berger et al. 2019).

\section{Variables}

In this section, we provide a brief overview of each variable and sufficient context to understand the particular usage in this study. The IEA has published detailed information about TIMSS scale development and psychometric properties, which the interested reader can find in Martin et al. (2016), as well as helpful usage guidance in Foy (2017).

\section{Demographics}

Student gender and parental educational attainment were selected as demographic variables given ongoing empirical interest in both gender and equity issues in mathematics and science education (Holmes et al. 2018). Student gender was recorded as a dichotomous variable as either girl (1) or boy (2). Each student provided data on their mother's and/or father's highest educational attainment, recorded in a single categorical variable showing the highest attainment of the two, with lower values indicating higher levels of parental education. Possible categories were as follows: (1) University or higher; (2) Post-secondary but not university; (3) Upper secondary; (4) Lower secondary; (5) Some primary, lower secondary, or no school; and (6) 


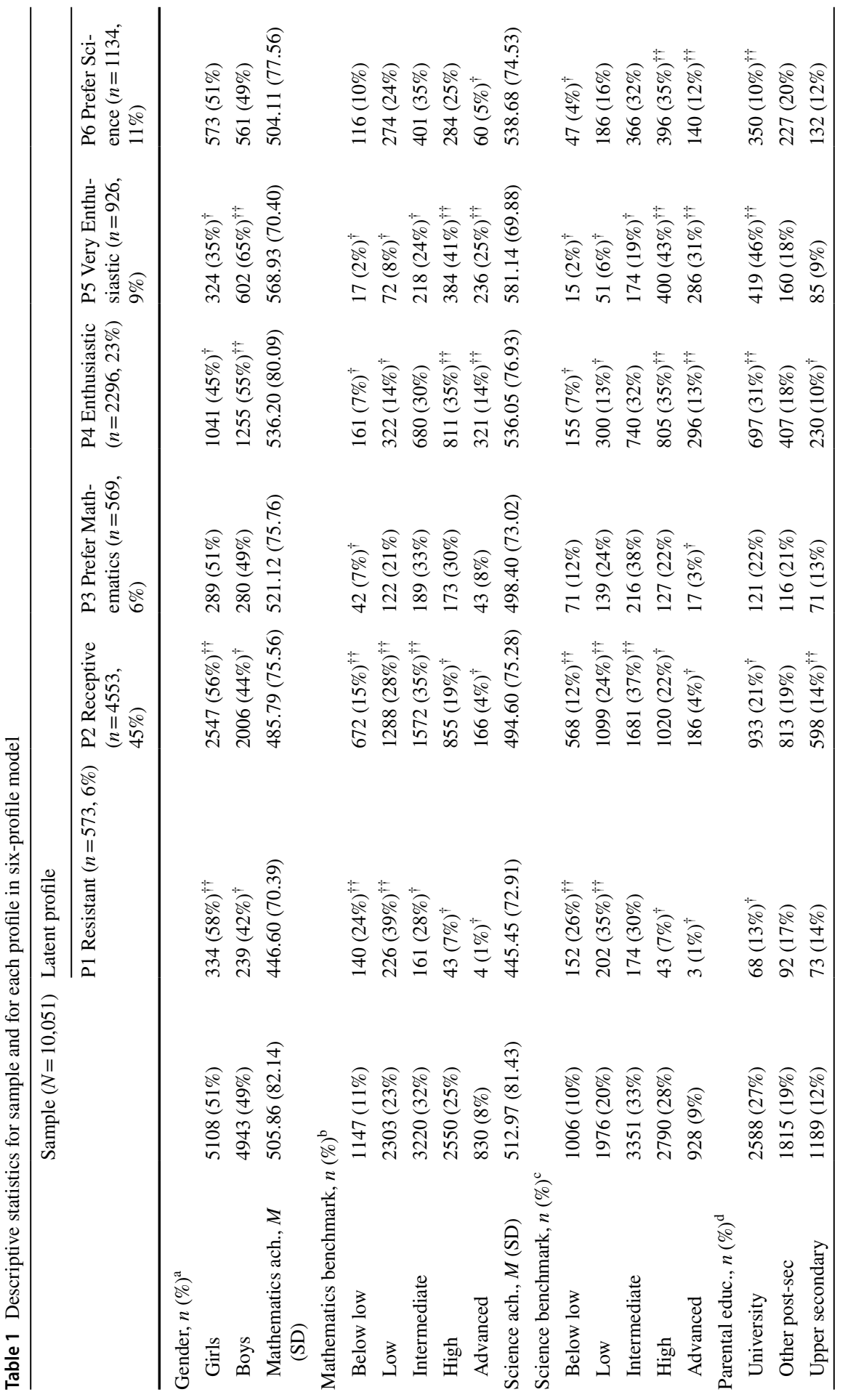




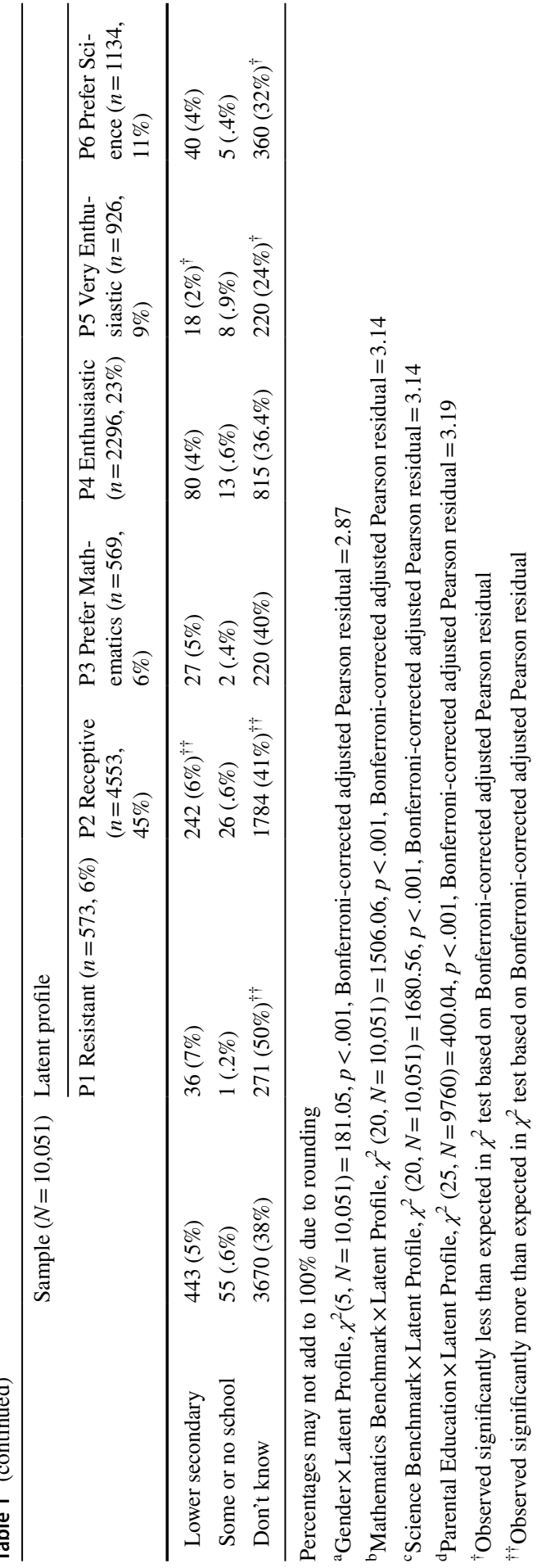


Don't know. The last category was retained as only categorical analyses were conducted with this variable.

\section{Mathematics achievement}

Student achievement in mathematics was recorded as achievement scores and corresponding achievement benchmarks. Mathematics achievement score was a continuous variable recorded as a series of five plausible values. Scores recorded in the first plausible value ranged from 184.97 to 767.16 , indicating a wide range of mathematics achievement demonstrated by participants. Mathematics achievement benchmark was a categorical variable recorded as a series of five plausible values. Possible values were as follows: (1) Below low; (2) Low; (3) Intermediate; (4) High; and (5) Advanced.

\section{Science achievement}

Student achievement in science was recorded as achievement scores and corresponding achievement benchmarks. Science achievement score was a continuous variable recorded as a series of five plausible values. Scores recorded in the first plausible value ranged from 185.04 to 780.11 , indicating a wide range of science achievement demonstrated by participants. Science achievement benchmark was a categorical variable recorded as a series of five plausible values. Possible values were as follows: (1) Below low; (2) Low; (3) Intermediate; (4) High; and (5) Advanced.

\section{Intrinsic value}

We operationalised mathematics intrinsic value using the TIMSS Students Like Learning Mathematics Scale, Eighth Grade (Cronbach's $\alpha=0.94$ ) and science intrinsic value using the TIMSS Students Like Learning Science Scale, Eighth Grade $(\alpha=0.93)$. For each scale, students responded to nine items (reproduced in the Appendix) using a four-point Likert scale ranging from Disagree a lot (0) through to Agree a lot (3). From these raw scores, the IEA constructed the scales using item response theory scaling methods, specifically the Rasch partial credit model (see Martin et al. 2016). Scales were constructed such that the mean score was 10 and the standard deviation was 2 across all countries participating in TIMSS. We use the transformed scale scores in this study.

\section{Self-concept}

We operationalised mathematics self-concept using the TIMSS Students Confident in Mathematics Scale, Eighth Grade $(\alpha=0.87)$ and science self-concept using the TIMSS Students Confident in Science Scale, Eighth Grade $(\alpha=0.90)$. Students responded to nine items related to mathematics and eight items related to science (reproduced in the Appendix) using the same Likert scale as for intrinsic value. As with intrinsic value, scale scores were constructed using the Rasch approach, and we use these transformed scale scores in this study. 


\section{Utility value}

We operationalised mathematics utility value using the TIMSS Students Value Mathematics Scale, Eighth Grade $(\alpha=0.90)$ and science utility value using the TIMSS Students Value Science Scale, Eighth Grade $(\alpha=0.94)$. For each scale, students responded to nine items (reproduced in the Appendix) using the same Likert scale as for intrinsic value. As with intrinsic value, we use the Rasch-transformed scale scores provided by IEA in this study.

\section{Analysis}

\section{Missing data}

The primary variables analysed in this paper were the six related to mathematics and science attitudes (i.e. intrinsic value, self-concept, and utility value in each subject). Complete data on these six variables were present for 9697 (93.8\%) of cases. We conducted missing data imputation in SPSS as the proportion of cases with missing data was over the $5 \%$ rule of thumb suggested in the literature (Dong and Peng 2013; Jakobsen et al. 2017). First, we listwise deleted 287 (2.8\%) cases missing data on all six variables. Second, Little's missing completely at random (MCAR) test showed the data were suited to expectation-maximisation (EM) imputation, $\chi^{2}=147.792, d f=150, p=0.536$. Finally, we used EM to impute data for $354(3.4 \%)$ cases. Thus, the final sample for analysis comprised 10,051 cases or $97.2 \%$ of the Australian Grade 8 students who participated in TIMSS 2015.

\section{Three-step approach}

We performed a three-step LPA (Van Montfort et al. 2017) using Mplus Version 8 and IBM SPSS Statistics Version 25. The first step was the identification of a latent profile model using an enumeration process which involved estimating models with increasing numbers of latent profiles in Mplus. Once a suitable model was identified, the second step involved assigning participants to latent profiles. In the third step, we tested whether various demographic and achievement variables were associated with latent profile membership using SPSS.

In the first step, Mplus was used to generate LPA models with increasing numbers of latent profiles. The six variables entered into the models were mathematics intrinsic value, mathematics self-concept, mathematics utility value, science intrinsic value, science self-concept, and science utility value (Table 2 reports correlations between these measures and achievement scores). The analysis type was mixture. For each of the models, the following fit statistics were produced: maximum log-likelihood (LL), Akaike Information Criterion (AIC), Bayesian Information Criterion (BIC), Sample Adjusted Bayesian Information Criterion (SABIC), Vuong-Lo-Mendell-Rubin Test (VLMR), and entropy. Initially, a single-profile model was produced, followed by a two-profile model, and so on until 
Table 2 Pearson correlations

\begin{tabular}{lllllllll}
\hline Measure & 1 & 2 & 3 & 4 & 5 & 6 & 7 & 8 \\
\hline 1. Mathematics intrinsic value & - & & & & & & \\
2. Mathematics self-concept & $.65^{* *}$ & - & & & & & \\
3. Mathematics utility value & $.55^{*}$ & $.38^{*}$ & - & & & & \\
4. Science intrinsic value & .30 & .17 & .30 & - & & & \\
5. Science self-concept & .20 & .28 & .21 & $.71^{* *}$ & - & & \\
6. Science utility value & .33 & .23 & $.50^{*}$ & $.63^{* *}$ & $.48^{*}$ & - & \\
7. Mathematics achievement & .34 & $.51^{*}$ & .23 & .21 & .24 & .26 & - \\
8. Science achievement & .23 & $.39 *$ & .21 & .34 & $.39 *$ & .32 & $.85^{* *}$ & - \\
\hline
\end{tabular}

$* p<.05$

$* * p<.001$

the fit statistics indicated an optimal solution had been reached, at which point model enumeration ceased.

Table 3 provides fit statistics generated during the profile enumeration process. Several fit statistics were used to evaluate models with increasing numbers of latent profiles. LL, AIC, BIC, and SABIC are information criteria which penalise model complexity, and hence models with lower values are preferred to models with higher values for these statistics (Schreiber and Pekarik 2014). These information criteria continued to decrease as the number of latent profiles increased during the enumeration process, indicating models with more profiles fitted better than models with fewer profiles. VLMR tests whether a model with $n$ profiles has a better fit compared to the model with $n-1$ profiles (Lo et al. 2001). For example, does the model with

Table 3 Fit statistics for models with different numbers of latent profiles

\begin{tabular}{|c|c|c|c|c|c|c|c|c|}
\hline \multicolumn{9}{|c|}{ Model with $n$ profiles } \\
\hline $\mathrm{M} n$ & $\begin{array}{l}\text { Log-likeli- } \\
\text { hood }\end{array}$ & $\begin{array}{l}\text { Free } \\
\text { param- } \\
\text { eters }\end{array}$ & AIC & $\mathrm{BIC}$ & SABIC & VLMR & Entropy & $\begin{array}{l}\text { Smallest } \\
\text { profile } n \\
(\%)\end{array}$ \\
\hline M2 & -121998.102 & 19 & 244034.205 & 244171.298 & 244110.919 & $<.001 *$ & .793 & $\begin{array}{l}3432 \\
(34 \%)\end{array}$ \\
\hline M3 & -120163.841 & 26 & 240379.682 & 240567.283 & 240484.659 & $<.001^{*}$ & .824 & $\begin{array}{l}1026 \\
(10 \%)\end{array}$ \\
\hline M4 & -119027.509 & 33 & 238121.018 & 238359.127 & 238254.258 & $<.001^{*}$ & .805 & $\begin{array}{l}1150 \\
(11 \%)\end{array}$ \\
\hline M5 & -117871.187 & 40 & 235822.374 & 236110.991 & 235983.877 & $<.001 *$ & .800 & $\begin{array}{l}624 \\
(6 \%)\end{array}$ \\
\hline M6 & -117084.356 & 47 & 234262.712 & 234601.837 & 234452.478 & $.011 *$ & .808 & $\begin{array}{l}569 \\
(6 \%)\end{array}$ \\
\hline M7 & -116630.108 & 54 & 233368.215 & 233757.848 & $233,586.244$ & .063 & .814 & $\begin{array}{l}414 \\
\quad(4 \%)\end{array}$ \\
\hline
\end{tabular}

* M $n$ has significantly better fit than $\mathrm{M} n-1$. Bold indicates selected model 
seven profiles fit better than the model with six profiles? Using this statistic, model enumeration can cease when a non-significant result is obtained, even when the information criteria continue to get smaller (Nyland et al. 2007). This occurred with the seven-profile model, indicating it did not fit the data significantly better than the six-profile model. Finally, higher entropy values indicate a clearer delineation of profiles (Celeux and Soromenho 1996). While the highest entropy was obtained in the three-profile model, the entropy value of the six-profile model was also high. Altogether, the fit statistics indicated the six-profile model was the best solution.

In the second step, the Mplus save command was used to create a new dataset with profile membership indicators for each student. As LPA produces a probabilistic model with each student given a likelihood of belonging to each profile, the highest or most probable likelihood was used to assign each student to a single latent profile. This dataset was then imported into SPSS for subsequent analyses.

In the third step, inferential statistical techniques were applied in SPSS to examine differences in mathematics and science achievement between latent profiles and between genders within latent profiles. As some statistical packages cannot handle plausible values used to record achievement scores, some researchers use 'shortcuts' such as using only the first or a random plausible value (Laukaityte and Wiberg 2017) or averaging the plausible values (Von Davier et al. 2009) to arrive at a single variable for use in their analyses. However, these approaches can produce biased estimates which, in the case of choosing a single or random plausible value, might vary greatly depending on which plausible value was chosen (Laukaityte and Wiberg 2017). As SPSS does not provide for the use of plausible values through its usual interface, analyses requiring the use of plausible values were set up using the IEA IDB Analyser software (see Foy 2017). The software produces custom SPSS scripts capable of handling plausible values. When run, the scripts perform analyses of achievement-related variables five times (once for each plausible value). The results are then aggregated to produce accurate estimates of achievement scores and their standard errors, which incorporate both sampling and imputation variance (Foy 2017).

\section{Results}

\section{The latent profile model}

\section{Naming the profiles}

Figure 1 illustrates the six-profile model by plotting mathematics and science attitudes in relation to one another and then grouping the points which form a single latent profile. For each of the attitudinal scales, the IEA has established reference values to indicate the relative strength of the attitude (see Martin et al. 2016). While the scale score cut-offs differ slightly for each attitude, we have generalised these to negative attitudes towards a subject (scores $\leq 8$ ), positive attitudes towards a subject (scores $>8$ but $<10$ ), and very positive attitudes towards a subject (scores $\geq 10$ ). These are illustrated as reference lines in Fig. 1 and enable 


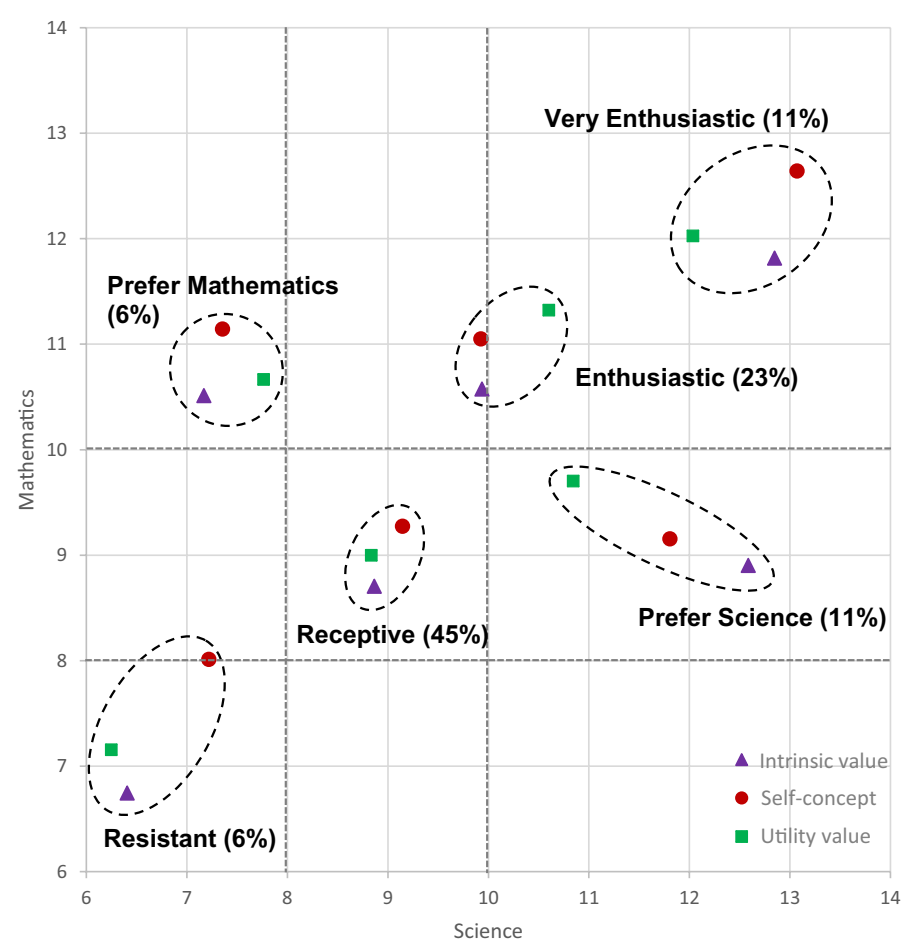

Fig. 1 Latent profiles in mathematics and science attitudes. Reference lines on the axes indicate whether students have negative attitudes towards a subject $(x, y \leq 8)$, positive attitudes towards a subject $(8<x$, $y<10)$, or very positive attitudes towards a subject $(x, y \geq 10)$

visual identification of whether, for example, students perceive no intrinsic value in mathematics, some intrinsic value in mathematics, or a high level of intrinsic value in mathematics. The reference values operate in similarly for each of the other mathematics and science attitudes.

Four of the six latent profiles were located along a positive diagonal axis, indicating increasingly positive attitudes to both mathematics and science. One latent profile was located within the part of the plot indicating very positive attitudes towards mathematics but negative attitudes towards science, while another latent profile was located in the region indicating very positive attitudes towards science and positive attitudes towards mathematics. Based on these patterns, we arrived at the profile names Resistant for students (6\%) who had negative attitudes towards both subjects, Receptive for students (45\%) who were positively disposed towards both mathematics and science, Enthusiastic for students (23\%) who had very positive attitudes towards both subjects but at the lower end of the scale, and Very Enthusiastic for students (11\%) who had very positive attitudes to both subjects and were located in the top right-hand corner of the plot. For the two groups not located along that diagonal continuum, we named one Prefer Mathematics and the other Prefer Science. However, it should be noted that these 
latent profiles do not parallel one another neatly, as the Prefer Science students (11\%) were more positive about mathematics than were the Prefer Mathematics students $(6 \%)$ towards science.

\section{General profile characteristics}

Table 1 reports descriptive statistics for each of the latent profiles, along with ChiSquare tests of association for categorical variables. We highlight some notable features here. First, there was an association between gender and the latent profiles, $\chi^{2}(5, N=10,051)=181.05, p<0.001$. While the Prefer Mathematics and Prefer Science profiles had approximately equal numbers of girls and boys, girls were observed more frequently (58\%) than expected in the Resistant profile, while girls were observed less frequently $(35 \%)$ than expected in the Very Enthusiastic profile. The Receptive and Enthusiastic profiles formed something of a continuum between these extremes.

Second, there was an association between the latent profiles and mathematics benchmarks $\left(\chi^{2}[20, N=10051]=1506.06, p<0.001\right)$ and science benchmarks $\left(\chi^{2}\right.$ $[20, N=10051]=1680.56, p<0.001)$. Students achieving at the advanced international benchmarks were observed more frequently than expected in the Very Enthusiastic profile for both mathematics $(25 \%)$ and science $(31 \%)$, and less frequently than expected in the Resistant profile for both mathematics (1\%) and science (1\%).

Third, there was an association between student-reported parental education and the latent profiles, $\chi^{2}(25, N=9760)=400.04, p<0.001$. Students who reported having university-educated parents were observed more frequently than expected in the Enthusiastic (31\%), Very Enthusiastic (46\%), and Prefer Science (10\%) profiles, and less frequently than expected in the Resistant (13\%) and Receptive (21\%) profiles. In terms of student knowledge of their parents' education, students who reported not knowing the qualifications held by their parents were observed more frequently than expected in the Resistant (50\%) and Receptive (41\%) profiles, and less frequently than expected in the Very Enthusiastic (24\%) and Prefer Science (32\%) latent profiles.

\section{Exploration of achievement, attitudes, and gender}

Achievement differences between latent profiles. As shown in Table 1, as the latent profiles' mean attitude scores increased, so did mathematics and science achievement scores. Table 4 reports $t$ test multiple comparisons between latent profiles to assess whether these observed differences in achievement were statistically significant. All of the latent profiles were significantly different from one another for mathematics achievement (all $p<0.01$ ). The Very Enthusiastic group was the highest achieving $(M=568.93, \mathrm{SD}=70.40)$ and the Resistant group was the lowest achieving $(M=446.60, \mathrm{SD}=70.39)$. Students in the Prefer Mathematics $(M=521.12$, $\mathrm{SD}=75.76)$ profile achieved better in mathematics than those in the Prefer Science $(M=504.11, \mathrm{SD}=77.56)$ or Receptive profiles $(M=485.79, \mathrm{SD}=75.56)$, but not as well as those in the Enthusiastic $(M=536.20, \mathrm{SD}=80.09)$ profile. Figure 2 shows 
Table 4 Multiple comparison of mean achievement scores between latent profiles

\begin{tabular}{|c|c|c|c|c|c|c|c|}
\hline \multirow[t]{2}{*}{ Subject } & Reference profile & $\begin{array}{l}\text { Comparison } \\
\text { profile }\end{array}$ & $\Delta \mathrm{M}(\Delta \mathrm{SD})$ & \multirow[t]{2}{*}{$t$} & \multirow[t]{2}{*}{$d f$} & \multirow[t]{2}{*}{$p$} & \multirow[t]{2}{*}{$d$} \\
\hline & $\mathrm{P} n M(\mathrm{SD})$ & $\mathrm{P} n M(\mathrm{SD})$ & & & & & \\
\hline \multirow[t]{15}{*}{ Mathematics } & \multirow[t]{5}{*}{ P1 446.60 (70.39) } & P2 485.79 (75.56) & 39.19 (103.27) & 7.99 & 5124 & $<.001 *$ & .54 \\
\hline & & P3 521.12 (75.76) & $74.53(103.41)$ & 11.34 & 1140 & $<.001 *$ & 1.02 \\
\hline & & P4 536.20 (80.09) & 89.61 (106.63) & 16.58 & 2867 & $<.001^{*}$ & 1.19 \\
\hline & & P5 568.93 (70.40) & $122.33(99.55)$ & 18.48 & 1497 & $<.001 *$ & 1.74 \\
\hline & & P6 504.11 (77.56) & $57.51(104.74)$ & 9.90 & 796 & $<.001^{*}$ & .78 \\
\hline & \multirow[t]{4}{*}{ P2 485.79 (75.56) } & P3 521.12 (75.76) & $35.34(107.00)$ & 6.54 & 5120 & $<.001 *$ & .47 \\
\hline & & P4 536.20 (80.09) & $50.41(110.11)$ & 16.26 & 6847 & $<.001 *$ & .65 \\
\hline & & P5 568.93 (70.40) & 83.14 (103.27) & 18.63 & 5477 & $<.001^{*}$ & 1.14 \\
\hline & & P6 504.11 (77.56) & $18.32(108.28)$ & 5.28 & 4776 & $<.001 *$ & .24 \\
\hline & \multirow[t]{3}{*}{ P3 $521.12(75.76)$} & P4 536.20 (80.09) & $15.08(110.25)$ & 2.98 & 2863 & $.002 *$ & .19 \\
\hline & & P5 568.93 (70.40) & $47.81(103.42)$ & 7.53 & 1493 & $<.001 *$ & .65 \\
\hline & & P6 $504.11(77.56)$ & $-17.01(108.42)$ & -2.57 & 792 & $.010^{*}$ & .22 \\
\hline & \multirow[t]{2}{*}{ P4 536.20 (80.09) } & P5 568.93 (70.40) & 32.73 (106.63) & 7.12 & 3220 & $<.001 *$ & .43 \\
\hline & & P6 504.11 (77.56) & $-32.09(111.49)$ & -7.99 & 2519 & $<.001 *$ & .41 \\
\hline & P5 568.93 (70.40) & P6 504.11 (77.56) & $-64.82(104.75)$ & -13.02 & 1149 & $<.001 *$ & .88 \\
\hline \multirow[t]{15}{*}{ Science } & \multirow[t]{5}{*}{ P1 445.45 (72.91) } & P2 494.60 (75.28) & $49.16(104.8)$ & 9.20 & 5124 & $<.001^{*}$ & .66 \\
\hline & & P3 498.40 (73.02) & 52.95 (103.19) & 7.82 & 1140 & $<.001 *$ & .73 \\
\hline & & P4 536.05 (76.93) & 90.60 (105.99) & 14.91 & 2867 & $<.001^{*}$ & 1.21 \\
\hline & & P5 581.14 (69.88) & $135.69(100.99)$ & 20.43 & 1497 & $<.001^{*}$ & 1.90 \\
\hline & & P6 538.68 (74.53) & $93.23(104.26)$ & 15.47 & 796 & $<.001^{*}$ & 1.26 \\
\hline & \multirow[t]{4}{*}{ P2 494.60 (75.28) } & P3 498.40 (73.02) & $3.79(104.88)$ & 0.72 & 5120 & .474 & .05 \\
\hline & & P4 $536.05(76.93)$ & 41.44 (107.64) & 13.82 & 6847 & $<.001^{*}$ & .54 \\
\hline & & P5 581.14 (69.88) & $86.53(102.71)$ & 19.26 & 5477 & $<.001^{*}$ & 1.19 \\
\hline & & P6 538.68 (74.53) & 44.07 (105.93) & 12.25 & 4776 & $<.001^{*}$ & .59 \\
\hline & \multirow[t]{3}{*}{ P3 498.40 (73.02) } & P4 536.05 (76.93) & 37.65 (106.07) & 7.54 & 2863 & $<.001^{*}$ & .50 \\
\hline & & P5 581.14 (69.88) & 82.74 (101.07) & 12.23 & 1493 & $<.001^{*}$ & 1.16 \\
\hline & & P6 538.68 (74.53) & 40.28 (104.34) & 6.12 & 792 & $<.001^{*}$ & .55 \\
\hline & \multirow[t]{2}{*}{ P4 536.05 (76.93) } & P5 581.14 (69.88) & 45.09 (103.93) & 9.95 & 3220 & $<.001 *$ & .61 \\
\hline & & P6 538.68 (74.53) & $2.63(107.11)$ & 0.59 & 2519 & .552 & .03 \\
\hline & P5 581.14 (69.88) & P6 538.68 (74.53) & $-42.46(102.17)$ & -8.43 & 1149 & $<.001 *$ & .59 \\
\hline
\end{tabular}

*Significant difference at $p<.05$ (two-tailed)

similar patterns in mathematics achievement in terms of international benchmark scores within each latent profile. In terms of science achievement, each profile was statistically different from the others (all $p<0.001$ ) with two exceptions. The Receptive $(M=494.60, \mathrm{SD}=75.28)$ and Prefer Mathematics $(M=498.40, \mathrm{SD}=73.02)$ profiles had similar science achievement scores to one another $(p=0.474)$, as did the Enthusiastic $(M=536.05, \mathrm{SD}=76.93)$ and Prefer Science $(M=538.68, \mathrm{SD}=74.53)$ latent profiles $(p=0.552)$. In a similar pattern to mathematics achievement, the Very Enthusiastic group $(M=581.14, \mathrm{SD}=69.88)$ had the highest science achievement, 


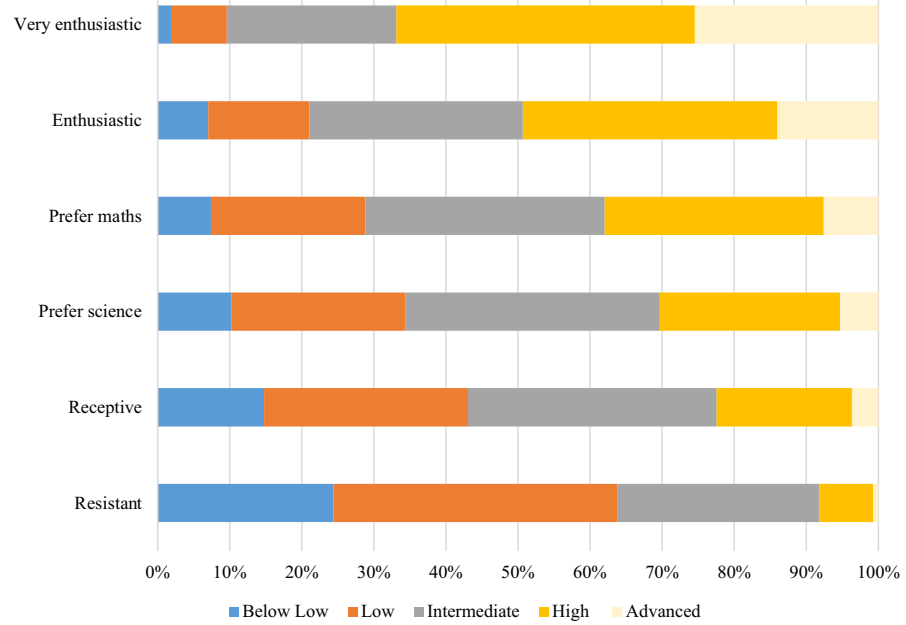

Fig. 2 International mathematics achievement benchmark distribution in each latent profile

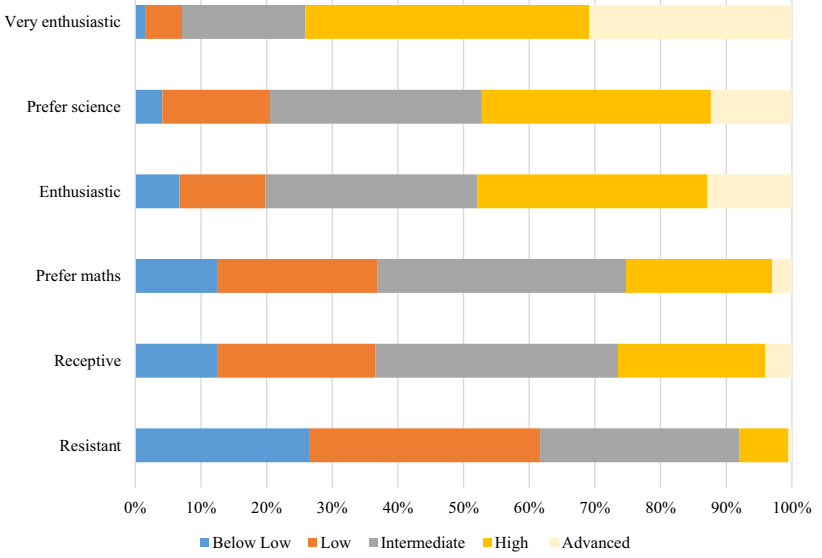

Fig. 3 International science achievement benchmark distribution in each latent profile

while the Resistant group $(M=445.45, \mathrm{SD}=72.91)$ had the lowest science achievement. Figure 3 further illustrates science achievement by highlighting the distribution in international benchmark scores within each latent profile.

\section{Achievement differences between genders in latent profiles}

Table 5 presents $t$ test multiple comparisons between the achievement scores of girls and boys in each latent profile. There were no significant differences between the genders within any latent profile in either mathematics or science achievement (all $p>0.05)$. 
Table 5 Multiple comparison of mean achievement scores between girls and boys in each latent profile

\begin{tabular}{|c|c|c|c|c|c|c|c|c|}
\hline Subject & $\begin{array}{l}\text { Profile } \\
\text { Pn }\end{array}$ & $\begin{array}{l}\text { Girls } \\
M(\mathrm{SD})\end{array}$ & $\begin{array}{l}\text { Boys } \\
M \text { (SD) }\end{array}$ & $\Delta \mathrm{M}(\Delta \mathrm{SD})$ & $t$ & $d f$ & $p$ & $d$ \\
\hline \multirow[t]{6}{*}{ Mathematics } & P1 & $440.16(72.73)$ & $457.11(64.99)$ & $16.95(97.54)$ & 1.78 & 571 & .076 & .25 \\
\hline & $\mathrm{P} 2$ & $488.97(75.80)$ & $481.73(75.07)$ & $-7.24(106.68)$ & -1.69 & 4551 & .092 & .10 \\
\hline & P3 & $526.51(74.51)$ & $516.04(76.55)$ & $-10.4(106.83)$ & -1.02 & 567 & .310 & .14 \\
\hline & P4 & $542.34(77.73)$ & $531.35(81.58)$ & $-11.0(112.68)$ & -1.81 & 2294 & .070 & .14 \\
\hline & P5 & $567.25(72.36)$ & $569.99(69.10)$ & $2.75(100.05)$ & .31 & 924 & .754 & .04 \\
\hline & P6 & $505.11(76.85)$ & $503.10(78.23)$ & $-2.01(109.66)$ & -.29 & 1132 & .774 & .03 \\
\hline \multirow[t]{6}{*}{ Science } & $\mathrm{P} 1$ & $438.44(73.44)$ & $456.89(70.45)$ & $18.46(101.77)$ & 1.90 & 571 & .058 & .26 \\
\hline & $\mathrm{P} 2$ & 497.05 (74.95) & $491.48(75.58)$ & $-5.57(106.44)$ & -1.45 & 4551 & .146 & .55 \\
\hline & P3 & $500.26(71.63)$ & $496.64(74.20)$ & $-3.62(103.13)$ & -.35 & 567 & .724 & .05 \\
\hline & P4 & 538.78 (72.99) & $533.89(79.84)$ & $-4.89(108.18)$ & -.89 & 2294 & .371 & .06 \\
\hline & P5 & $577.54(73.04)$ & $583.42(67.69)$ & 5.87 (99.58) & .71 & 924 & .478 & .08 \\
\hline & P6 & $536.45(73.79)$ & $540.93(75.16)$ & $4.48(105.33)$ & .67 & 1132 & .502 & .06 \\
\hline
\end{tabular}

*Significant difference at $p<.05$ (two-tailed)

\section{Attitudinal differences between latent profiles}

Table 6 presents a multivariate analysis of variance (MANOVA) of mathematics and science attitudes between the latent profiles. The general finding that attitudes differed significantly between the latent profiles $(p<0.05)$ was to be expected given the LPA sought to distinguish groups using these variables. However, similarities between some profiles emerged in some attitudinal variables $(p>0.05)$. Students in the Prefer Mathematics $(M=10.69, \mathrm{SD}=1.44)$ profile had similar mathematics intrinsic value scores to students in the Enthusiastic $(M=10.65, \mathrm{SD}=1.31)$ profile. Students in Prefer Mathematics $(M=11.36$, $\mathrm{SD}=1.77)$ also had similar mathematics self-concept scores to students in the Enthusiastic $(M=11.14, \mathrm{SD}=1.69)$ profile. However, Enthusiastic students $(M=11.44, \mathrm{SD}=1.39)$ had higher mathematics utility value scores than the Prefer Mathematics $(M=10.82, \mathrm{SD}=1.64)$ students. Students in the Prefer Science $(M=8.85, \mathrm{SD}=1.42)$ profile had similar mathematics intrinsic value scores to students in the Receptive $(M=8.68, \mathrm{SD}=1.26)$ group. Students in the Prefer Science $(M=9.09, \mathrm{SD}=1.66)$ group also had similar mathematics self-concept scores to students in the Receptive $(M=9.25, \mathrm{SD}=1.51)$ latent profile. However, students in Prefer Science $(M=9.65, \mathrm{SD}=1.60)$ perceived higher mathematics utility value than students in the Receptive $(M=8.97, \mathrm{SD}=1.27)$ profile. In terms of science attitudes, only one similarity between groups was noted. Students in the Resistant $(M=7.13, \mathrm{SD}=1.97)$ profile had similar science self-concept scores to students in the Prefer Mathematics $(M=7.16, \mathrm{SD}=1.84)$ profile. 


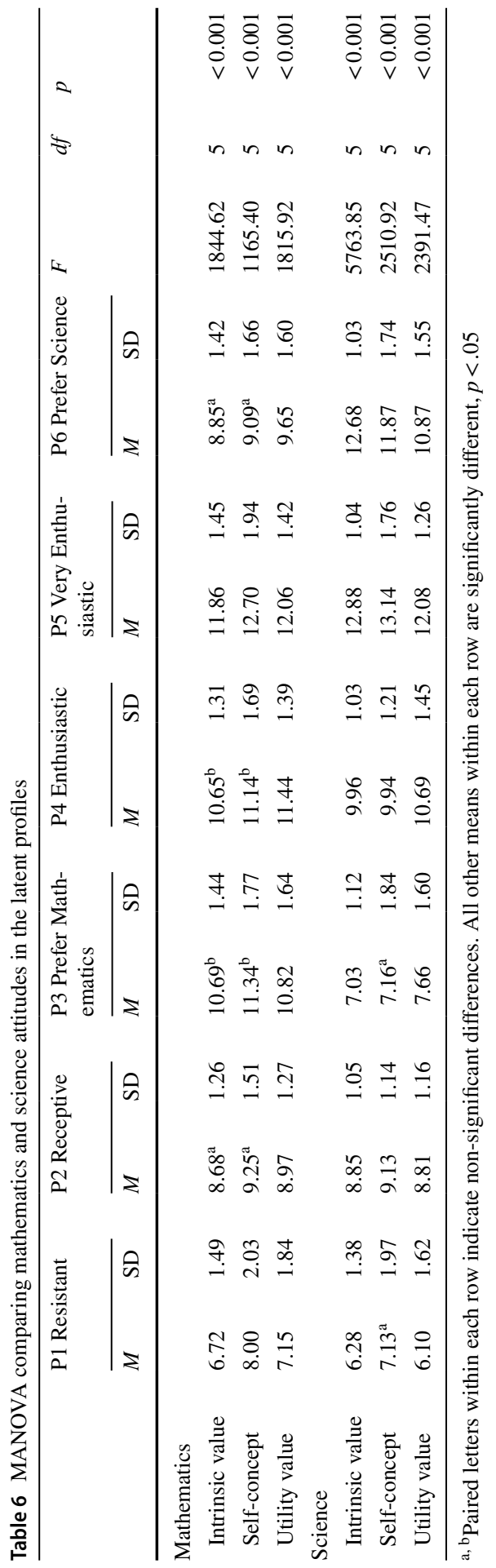


Table 7 Multiple comparison of mean attitude scores between girls and boys in each latent profile

\begin{tabular}{|c|c|c|c|c|c|c|c|c|c|}
\hline Subject & Attitude & $\begin{array}{l}\text { Profile } \\
\mathrm{Pn}\end{array}$ & $\begin{array}{l}\text { Girls } \\
M(\mathrm{SD})\end{array}$ & $\begin{array}{l}\text { Boys } \\
M \text { (SD) }\end{array}$ & $\Delta \mathrm{M}(\Delta \mathrm{SD})$ & $t$ & $d f$ & $p$ & $d$ \\
\hline \multirow{18}{*}{$\begin{array}{l}\text { Mathemat- } \\
\text { ics }\end{array}$} & \multirow{6}{*}{$\begin{array}{l}\text { Intrinsic } \\
\text { value }\end{array}$} & $\mathrm{P} 1$ & $6.72(1.43)$ & $6.80(1.62)$ & $.08(2.16)$ & .42 & 571 & .676 & .05 \\
\hline & & $\mathrm{P} 2$ & $8.59(1.28)$ & $8.80(1.17)$ & $.22(1.73)$ & 4.67 & 4551 & $<.001 *$ & .17 \\
\hline & & P3 & $\begin{array}{r}10.62 \\
(1.33)\end{array}$ & $\begin{array}{l}10.76 \\
(1.48)\end{array}$ & .14 (1.99) & .86 & 567 & .390 & .10 \\
\hline & & $\mathrm{P} 4$ & $\begin{array}{r}10.58 \\
(1.29)\end{array}$ & $\begin{array}{c}10.63 \\
(1.28)\end{array}$ & $.05(1.82)$ & .67 & 2294 & .502 & .04 \\
\hline & & P5 & $\begin{array}{l}11.68 \\
(1.41)\end{array}$ & $\begin{array}{l}11.90 \\
(1.51)\end{array}$ & $.23(2.07)$ & 1.56 & 924 & .119 & .15 \\
\hline & & P6 & $8.69(1.57)$ & $8.88(1.45)$ & $.20(2.14)$ & 1.63 & 1132 & .104 & .13 \\
\hline & \multirow{6}{*}{$\begin{array}{l}\text { Self-con- } \\
\text { cept }\end{array}$} & $\mathrm{P} 1$ & $7.51(2.05)$ & $8.68(1.74)$ & 1.17 (2.69) & 5.70 & 571 & $<.001 *$ & .62 \\
\hline & & $\mathrm{P} 2$ & $9.00(1.62)$ & 9.51 (1.39) & $.52(2.13)$ & 9.68 & 4551 & $<.001 *$ & .34 \\
\hline & & P3 & $\begin{array}{l}11.11 \\
\quad(1.76)\end{array}$ & $\begin{array}{r}11.46 \\
(1.68)\end{array}$ & $.35(2.43)$ & 1.82 & 567 & .069 & .20 \\
\hline & & $\mathrm{P} 4$ & $\begin{array}{r}11.08 \\
(1.69)\end{array}$ & $\begin{array}{c}11.26 \\
(1.78)\end{array}$ & $.17(2.45)$ & 1.55 & 2294 & .121 & .10 \\
\hline & & P5 & $\begin{array}{r}12.29 \\
(1.89)\end{array}$ & $\begin{array}{r}12.30 \\
(1.97)\end{array}$ & $.44(2.73)$ & 2.17 & 924 & $.030 *$ & .01 \\
\hline & & P6 & $8.94(1.74)$ & $9.20(1.68)$ & $.26(2.42)$ & 1.98 & 1132 & $.048 *$ & .15 \\
\hline & \multirow[t]{6}{*}{$\begin{array}{l}\text { Utility } \\
\text { value }\end{array}$} & $\mathrm{P} 1$ & $7.17(2.00)$ & $7.11(1.77)$ & $\begin{array}{l}-.06 \\
(2.67)\end{array}$ & -.25 & 571 & .806 & .03 \\
\hline & & $\mathrm{P} 2$ & $8.91(1.30)$ & $9.09(1.30)$ & $.18(1.84)$ & 3.69 & 4551 & $<.001 *$ & .14 \\
\hline & & P3 & $\begin{array}{r}10.77 \\
(1.59)\end{array}$ & $\begin{array}{r}11.01 \\
(1.63)\end{array}$ & $.23(2.28)$ & 1.27 & 567 & .205 & .15 \\
\hline & & $\mathrm{P} 4$ & $\begin{array}{r}11.32 \\
(1.33)\end{array}$ & $\begin{array}{r}11.62 \\
(1.41)\end{array}$ & $.30(1.94)$ & 3.85 & 2294 & $<.001 *$ & .22 \\
\hline & & P5 & $\begin{array}{l}11.91 \\
(1.41)\end{array}$ & $\begin{array}{l}12.05 \\
(1.44)\end{array}$ & $.14(2.02)$ & 1.06 & 924 & .291 & .09 \\
\hline & & P6 & $9.58(1.64)$ & $9.67(1.62)$ & $.08(2.31)$ & .70 & 1132 & .483 & .06 \\
\hline
\end{tabular}


Table 7 (continued)

\begin{tabular}{|c|c|c|c|c|c|c|c|c|c|}
\hline Subject & Attitude & $\begin{array}{l}\text { Profile } \\
\mathrm{P} n\end{array}$ & $\begin{array}{l}\text { Girls } \\
M(\mathrm{SD})\end{array}$ & $\begin{array}{l}\text { Boys } \\
M(\mathrm{SD})\end{array}$ & $\Delta \mathrm{M}(\Delta \mathrm{SD})$ & $t$ & $d f$ & $p$ & $d$ \\
\hline \multirow[t]{18}{*}{ Science } & \multirow[t]{6}{*}{$\begin{array}{c}\text { Intrinsic } \\
\text { value }\end{array}$} & $\mathrm{P} 1$ & $6.38(1.35)$ & $6.34(1.56)$ & $\begin{array}{r}-.05 \\
\quad(2.06)\end{array}$ & .27 & 571 & .790 & .02 \\
\hline & & $\mathrm{P} 2$ & $8.82(1.04)$ & $8.87(1.06)$ & .05 (1.48) & 1.40 & 4551 & .162 & .05 \\
\hline & & P3 & $7.12(1.02)$ & $7.00(1.09)$ & $\begin{array}{r}-.12 \\
\quad(1.49)\end{array}$ & 1.04 & 567 & .298 & .11 \\
\hline & & $\mathrm{P} 4$ & $9.96(1.04)$ & $\begin{array}{l}10.00 \\
(1.09)\end{array}$ & $.05(1.51)$ & .66 & 2294 & .510 & .04 \\
\hline & & P5 & $\begin{array}{l}12.90 \\
(1.03)\end{array}$ & $\begin{array}{l}12.90 \\
(1.02)\end{array}$ & $0(1.45)$ & 0 & 924 & .997 & 0 \\
\hline & & P6 & $\begin{array}{r}12.64 \\
(1.02)\end{array}$ & $\begin{array}{l}12.75 \\
(1.03)\end{array}$ & $.11(1.45)$ & 1.25 & 1132 & .210 & .11 \\
\hline & \multirow{6}{*}{$\begin{array}{l}\text { Self-con- } \\
\text { cept }\end{array}$} & $\mathrm{P} 1$ & $6.82(2.00)$ & $7.64(1.84)$ & $.82(2.72)$ & 3.17 & 571 & $.002 *$ & .43 \\
\hline & & $\mathrm{P} 2$ & $9.02(1.21)$ & $9.24(1.06)$ & $.21(1.61)$ & 5.39 & 4551 & $<.001 *$ & .14 \\
\hline & & P3 & $7.01(1.72)$ & $7.45(2.04)$ & $.45(2.67)$ & 1.84 & 567 & .067 & .23 \\
\hline & & $\mathrm{P} 4$ & $9.82(1.22)$ & $9.94(1.18)$ & $.12(1.7)$ & 1.97 & 2294 & $.049 *$ & .09 \\
\hline & & P5 & $\begin{array}{l}12.91 \\
\quad(1.80)\end{array}$ & $\begin{array}{l}13.21 \\
\quad(1.78)\end{array}$ & $.30(2.53)$ & 1.57 & 924 & .116 & .18 \\
\hline & & P6 & $\begin{array}{r}11.67 \\
(1.67)\end{array}$ & $\begin{array}{l}12.11 \\
\quad(1.87)\end{array}$ & $.44(2.51)$ & 3.21 & 1132 & $.001^{*}$ & .25 \\
\hline & \multirow{6}{*}{$\begin{array}{l}\text { Utility } \\
\text { value }\end{array}$} & $\mathrm{P} 1$ & $6.20(1.60)$ & $5.77(1.54)$ & $-.43(2.22)$ & -2.62 & 571 & $.009 *$ & .27 \\
\hline & & $\mathrm{P} 2$ & $8.74(1.20)$ & $8.76(1.09)$ & $.02(1.62)$ & .53 & 4551 & .593 & .02 \\
\hline & & P3 & $7.89(1.44)$ & 7.38 (1.63) & $\begin{aligned}- & .51 \\
& (2.17)\end{aligned}$ & -2.69 & 567 & $.007 *$ & .36 \\
\hline & & $\mathrm{P} 4$ & $\begin{array}{r}10.77 \\
(1.45)\end{array}$ & $\begin{array}{r}10.55 \\
(1.49)\end{array}$ & $\begin{aligned} &- .22 \\
&(2.08)\end{aligned}$ & -2.37 & 2294 & $.018^{*}$ & .15 \\
\hline & & P5 & $\begin{array}{r}12.07 \\
(1.21)\end{array}$ & $\begin{array}{r}11.92 \\
(1.38)\end{array}$ & $\begin{array}{l}-.15 \\
(1.84)\end{array}$ & -1.40 & 924 & .161 & .12 \\
\hline & & P6 & $\begin{array}{l}10.76 \\
(1.61)\end{array}$ & $\begin{array}{r}10.97 \\
(1.55)\end{array}$ & $.21(2.23)$ & 1.65 & 1132 & .098 & .13 \\
\hline
\end{tabular}

*Significant difference at $p<.05$ (two-tailed)

\section{Attitudinal differences between genders in latent profiles}

Table 7 presents $t$ test multiple comparisons of attitudinal variables between boys and girls within each latent profile. All of the statistically significant differences in mathematics attitudes were in favour of boys, $p<0.05$. In the Receptive profile, boys $(M=8.80, \mathrm{SD}=1.17)$ had higher mathematics intrinsic value scores than girls $(M=8.59, \mathrm{SD}=1.28)$. Boys had higher mathematics self-concept than girls 
in all profiles except the Prefer Mathematics and Receptive profiles, and higher mathematics utility value than girls in the Receptive and Enthusiastic latent profiles (see Table 7 for scores). The picture with science attitudes was a little more complex. There were no differences between the genders in terms of science intrinsic value, $p>0.05$. Boys had higher science self-concept than girls in the Receptive, Enthusiastic, and Prefer Science latent profiles (see Table 7). However, girls saw more utility value in science than boys in the Resistant, Prefer Mathematics, and Enthusiastic profiles (see Table 7).

\section{Discussion}

\section{Positive attitudes are mutually beneficial}

\section{Summary}

Our analysis of TIMSS 2015 revealed six discrete groupings of adolescent attitudes towards both mathematics and science. While there was a small group of Resistant students $(6 \%)$ who had negative attitudes and poor achievement in both subjects, most students $(79 \%)$ were Receptive, Enthusiastic, or Very Enthusiastic towards both subjects and had at least intermediate levels of achievement in both. In general, the findings demonstrated that most students' attitudes towards mathematics and science were aligned and more positive attitudes were associated with better achievement (although causality could not be established by our analysis). Furthermore, this alignment of mathematics and science attitudes suggested that the majority of adolescents in this sample viewed mathematics and science in similar ways, given that their self-concept in the two subjects was relatively similar (Helm et al. 2016). The broad alignment between attitudes towards mathematics and science was encouraging given mathematics is integral to most of the sciences and that self-concept in mathematics can influence intentions to take science-based courses in further and higher education (Douglas and Attewell 2017; Mau 2003).

\section{Single-subject preferences}

While four of the student groups held relatively equivalent attitudes towards both mathematics and science, we identified two groups of students with a clear preference for one subject over the other. Those students in Prefer Science also held positive views of mathematics. This may be because mathematics underpins many scientific concepts and, as a result, weak mathematics skills are recognised as a potential barrier for learning in science (Karakas 2018). In contrast, the Prefer Mathematics group held negative attitudes to science, possibly indicating that they viewed mathematics as being quite distinct from science and able to be studied without dependence on science knowledge. While further investigation is required, adolescents in the Prefer Mathematics and Prefer Science groups may have viewed mathematics and science as dissimilar subjects (Helm et al. 2016), and their comparatively negative self-concept in the non-preferred subject was due to a contrasting internal frame 
of reference effect (Jansen et al. 2015). The implication for practice is that teachers need to emphasise the interrelated nature of many mathematical and scientific concepts and skills to support positive attitudes in both of those subjects.

Of the two groups with disproportionate attitudes to mathematics and science, the Prefer Science group is potentially at greater risk. The students in this group expressed very positive attitudes towards science, but as their mathematics attitudes were relatively less positive, they may reach a point where they are unable to continue to pursue science as they progress into the senior years of secondary school. This Prefer Science group and the larger Receptive group had similar attitudes to mathematics; however, the Prefer Science group expressed more positive attitudes to science, particularly in terms of their intrinsic valuing of science. In fact, the degree to which they liked the subject is on a par with the Very Enthusiastic group. In terms of achievement, the groups that had a clear preference for one subject over another generally achieved more highly than the Resistant and Receptive groups; however, they achieved at a lower (mathematics) or equivalent (science) rate compared to the Enthusiastic group, whose attitudes to both subjects aligned. We suggest, therefore, that while possessing positive attitudes in both subjects is most beneficial, that having very positive attitudes in at least one subject is more beneficial than moderate or low attitudes in both.

It should be noted here that students responded to items about science as a singular subject and therefore distinctions between student attitudes to particular science subjects (e.g. physics, chemistry, biology) could not be determined. It could be that the students in the Prefer Science group had a greater tendency towards biology rather than sciences with a greater dependency on mathematics skills, such as chemistry and physics. Across the full sample, $45 \%$ of students indicated very positive attitudes to science in Grade 8 (i.e. total number of students in the Prefer Science, Enthusiastic, and Very Enthusiastic latent profiles). Significantly, almost one-quarter of those students could be at risk due to their relatively poorer attitudes towards mathematics. While science teachers may be primarily concerned with student attitudes to science, this finding indicates that they should also be concerned about student attitudes to mathematics, particularly for those students who express very positive attitudes towards science. Given previous studies have confirmed the importance of intrinsic and utility values in adolescents' future subject selections (Watt et al. 2012), highlighting the importance of mathematics for science understanding and strategies to increase interest in mathematics may be particularly useful for students such as those in the Prefer Science group.

\section{A nuanced picture of gender differences}

\section{Attitudes}

Gender differences in self-concept, intrinsic values, and utility values in mathematics and science are a common feature of the literature. It has been noted that boys tend to have greater self-concept in mathematics than girls of equal ability (Louis and Mistelle 2012), and previous analysis of TIMSS 2015 observed higher levels of 
self-concept among boys in mathematics (Thomson et al. 2017). Our latent profile analysis provided some nuance by indicating differences in some latent profiles but not others. While self-concept differences in each latent profile were generally in favour of boys, girls held similar ability beliefs in mathematics if they were in the Prefer Mathematics or Enthusiastic groups, and similar ability beliefs in science if they were in the Resistant, Prefer Mathematics, and Very Enthusiastic groups. Given that self-concept can be influenced by a range of internal and external factors (Marsh 1986), a focus of future research could be to examine why girls in these groups have similar ability beliefs to boys, as such an understanding could be used to better support girls in the other latent profiles. We also noted what could be interpreted as inflated self-concept in Mathematics among boys in the relatively lower-achieving Resistant latent profile, as their greater self-concept compared to girls had the largest effect size $(d=0.62)$ of any noted for attitudinal differences. This finding aligns with previous research that found that, relative to boys, girls' achievement in mathematics had a larger effect on their self-concept in mathematics (Correll 2001). In contrast, we found that girls in the Very Enthusiastic latent profile had lower mathematical self-concept than boys, despite their high achievement. One explanation for this finding is that girls' self-concept was influenced by external comparisons with highachieving peers in this profile (Marsh et al. 2008). While further research is needed, these findings collectively suggest that girls in different latent profiles may require different strategies to support their mathematics and science self-concept.

While previous research has shown that girls' intrinsic valuing of mathematics was lower than boys among Australian adolescents (Watt et al. 2012), we only observed a gender difference in the Receptive latent profile. Boys liked mathematics more than girls in this profile, although the effect size was small by conventional standards $(d=0.17)$ according to Cohen (1988) who suggested that an effect size is small if less than 0.2, medium if between 0.2 and 0.5 , and large if greater than 0.5. One explanation for this finding is that girls and boys in the Receptive profile may have differed in their perceptions of learning activities designed to promote interest in mathematics. In either case, we argue that strategies to increase enjoyment and interest for girls in this group should be considered, given the importance of intrinsic value for continued study of mathematics (Watt et al. 2012). We found no gender differences for intrinsic valuing of science, suggesting that boys and girls display similar levels of enjoyment and interest in science within each latent profile.

We observed several gender differences in utility value within the latent profiles, with these differences favouring boys in mathematics and girls in science. While previous research with Australian adolescents found that there was no significant gender difference in mathematics utility value (Watt 2004, 2006), boys had significantly higher mathematics utility value in the Receptive and Enthusiastic profiles in our study. It is possible that our finding reflects a shift in how the importance of mathematics is communicated to some girls in Australia over time, although we strongly recommend further investigation of this possibility in future research. Girls valued science more than boys in the Resistant, Prefer Mathematics, and Enthusiastic profiles. Given the relatively negative science attitudes of the Resistant and Prefer Mathematics groups, this may be interpreted as girls in these groups being more 
likely to believe that science is valuable despite having poorer self-concept in science (Else-Quest et al. 2013).

\section{Achievement}

Previous analysis of TIMSS 2015 came to the notable conclusion of no gender differences among Australian Grade 8 students in terms of mathematics or science achievement (Thomson et al. 2017). While our analysis also found no statistically significant gender differences in mean mathematics and science achievement scores in each latent profile, we did observe an uneven distribution of boys and girls in the latent profiles. Among students who expressed a preference for one subject over the other, there was an approximately even distribution of boys and girls. However, girls were overrepresented in the Resistant latent profile compared to boys. At the other extreme, girls were underrepresented in the Very Enthusiastic latent profile compared to boys. As such, adolescent girls and boys with similar attitudes had the same levels of achievement, but there were fewer girls in the groups which represented more positive attitudes towards both mathematics and science. A previous latent profile analysis of adolescents' self-concept in different school subjects found that girls were underrepresented in the high mathematics-related self-concept group (Sass and Kampa 2019). Similarly, Watt et al. (2019) observed a greater proportion of girls were motivationally disengaged with mathematics compared to boys, as girls perceived higher costs for participation in that subject. Our study has added to this picture by finding that girls were underrepresented in the group that had a very positive self-concept, intrinsic value, and utility values in mathematics and science. This finding is important as it demonstrates that while there were no overall achievement differences between boys and girls, attitudinal profiles did differ by gender, and girls tended to have less favourable attitudes towards mathematics and science than boys. Given efforts to improve female representation in these disciplines, understanding that the key contributor appears to be attitudes and not achievement provides a focal point for future intervention.

\section{Supporting girls in science and mathematics}

There has been longstanding concern about girls' lower participation rates and aspirations in STEM fields compared to boys, with various complex and interrelated barriers becoming the subject of intervention efforts (Holmes et al. 2018). While our latent profile analysis confirmed the broad attitudinal differences already known to exist between boys and girls, the benefit of this person-centred method is the uncovering of the different types of attitudinal groupings to which boys and girls belong. As such, researchers and equity practitioners engaged in efforts to increase female uptake of STEM education might find the differing characteristics of these groups useful in targeting specific needs. It could be the case that girls with different attitudes towards mathematics and science need different activities to support their achievement and aspirations in those disciplines during secondary schooling and beyond. 


\section{Limitations and future research}

There are several limitations to this study which should be noted. First, while the sample was representative of Australian early-adolescents, caution should be exercised in generalising these findings to other country and age contexts, particularly in light of past research that has shown that some attitudes towards STEM subjects vary by country (e.g. Watt et al. 2012), and during childhood (e.g. Jacobs et al. 2002) and adolescence (e.g. Watt 2004). Second, while we noted associations between latent profile membership and achievement in mathematics and science, our analyses were not designed to test for causality either way. The chicken-and-egg question of whether positive attitudes result in higher achievement, or the other way around, remains unaddressed here. However, previous research has indicated it is a complex bidirectional relationship (Lee et al. 2015). Finally, while our interest in this question was prompted by declining enrolments in higher levels of mathematics and science in the senior years of schooling, the data do not allow us to connect latent profile membership in Grade 8 to actual subject selections in Grades 11 and 12. These limitations open avenues for further research.

In this study, we limited our focus to identifying the latent profile structure in the Australian Grade 8 TIMSS 2015 sample and exploring the associations between those attitudinal latent profiles, gender, and achievement scores. The TIMSS dataset contains other variables of interest which might be interesting to examine with these latent profiles, such as students' perceptions about engaging teaching in each subject. Consideration of negatively valenced motivation factors (e.g. costs in expectancy-value theory) could also be interesting. Future research using LPA might also examine the latent profile structure among the Grade 4 sample and in other countries. An interesting question arising from this study is whether younger students are more positive about both subjects than older students, and, relatedly, whether the latent profile structures might change between childhood and adolescence. Similarly, cross-country investigations that compare the latent profile structures and associations with gender between countries with different subject rankings may also be illuminating for researchers and practitioners.

\section{Conclusion}

In this study, we used latent profile analysis to jointly investigate the attitudes of Australian adolescents towards mathematics and science. The novel contribution of our findings is that the most adaptive attitudes for student achievement in each subject are those which are positive to both subjects. Where others have noted that mathematics acts as a "gatekeeper" for further study in the sciences (Douglas and Attewell 2017), we also contend that science presents an applied avenue for school students to appreciate the practical utility of mathematical concepts and 
skills. Given economic projections indicate that careers in fields that integrate mathematics and science will be increasingly prevalent in the twenty-first century, it is important for educators to understand the mutual benefit of positive attitudes towards both subjects. Using the latent profiles we have identified as a heuristic for the different types of students in their classes, mathematics and science teachers can tailor their pedagogical approaches to foster student enjoyment, self-concept, and perceived value in these vitally important subjects.

\section{Appendix}

\section{Items comprising each of the TIMSS attitudinal scales}

Items reproduced from Martin et al. (2016). An asterisk (*) indicates a reversecoded item.

\section{Students like learning mathematics scale, eighth grade}

1. I enjoy learning mathematics.

2. I wish I did not have to study mathematics*.

3. Mathematics is boring*.

4. I learn many interesting things in mathematics.

5. I like mathematics.

6. I like any schoolwork that involves numbers.

7. I like to solve mathematics problems.

8. I look forward to mathematics class.

9. Mathematics in one of my favourite subjects.

\section{Students confident in mathematics scale, eighth grade}

1. I usually do well in mathematics.

2. Mathematics is more difficult for me than for many of my classmates*.

3. Mathematics is not one of my strengths*.

4. I learn things quickly in mathematics.

5. Mathematics makes me nervous*.

6. I am good at working out difficult mathematics problems.

7. My teacher tells me I am good at mathematics.

8. Mathematics is harder for me than any other subject*.

9. Mathematics makes me confused*.

\section{Students value mathematics scale, eighth grade}

1. I think learning mathematics will help me in my daily life.

2. I need mathematics to learn other school subjects.

3. I need to do well in mathematics to get into the university of my choice.

4. I need to do well in mathematics to get the job I want. 
5. I would like a job that uses mathematics.

6. It is important to learn about mathematics to get ahead in the world.

7. Learning mathematics will give me more job opportunities when I am an adult.

8. My parents think it is important that I do well in mathematics.

9. It is important to do well in mathematics.

\section{Students like learning science scale, eighth grade}

1. I enjoy learning science.

2. I wish I did not have to study science*.

3. Science is boring*.

4. I learn many interesting things in science.

5. I like science.

6. I look forward to learning science in school.

7. Science teaches me how things in the world work.

8. I like to conduct science experiments.

9. Science is one of my favourite subjects.

\section{Students confident in science scale, eighth grade}

1. I usually do well in science

2. Science is more difficult for me than for many of my classmates*.

3. Science is not one of my strengths*.

4. I learn things quickly in science.

5. I am good at working out difficult science problems.

6. My teacher tells me I am good at science.

7. Science is harder for me than any other subject*.

8. Science makes me confused*.

\section{Students value science scale, eighth grade}

1. I think learning science will help me in my daily life.

2. I need science to learn other school subjects.

3. I need to do well in science to get into the university of my choice.

4. I need to do well in science to get the job I want.

5. I would like a job that involves using science.

6. It is important to learn about science to get ahead in the world.

7. Learning science will give me more job opportunities when I am an adult.

8. My parents think that it is important that I do well in science.

9. It is important to do well in science. 


\section{References}

Ahmed, W., van der Werf, G., Kuyper, H., \& Minnaert, A. (2013). Emotions, self-regulated learning, and achievement in mathematics: A growth curve analysis. Journal of Educational Psychology, 105(1), 150-161. https://doi.org/10.1037/a0030160.

Ainley, M., \& Ainley, J. (2011a). A cultural perspective on the structure of student interest in science. International Journal of Science Education, 33(1), 51-71. https://doi.org/10.1080/09500 693.2010.518640.

Ainley, M., \& Ainley, J. (2011b). Student engagement with science in early adolescence: The contribution of enjoyment to students' continuing interest in learning about science. Contemporary Educational Psychology, 36(1), 4-12. https://doi.org/10.1016/j.cedpsych.2010.08.001.

Bae, C. L., \& DeBusk-Lane, M. (2018). Motivation belief profiles in science: Links to classroom goal structures and achievement. Learning and Individual Differences, 67, 91-104. https://doi. org/10.1016/j.lindif.2018.08.003.

Berger, N., Hanham, J., Stevens, C. J., \& Holmes, K. (2019). Immediate feedback improves career decision self-efficacy and aspirational alignment. Frontiers in Psychology, 10, 1-5. https://doi. org/10.3389/fpsyg.2019.00255.

Betz, N. E., \& Hackett, G. (1983). The relationship of mathematics self-efficacy expectations to the selection of science-based college majors. Journal of Vocational Behavior, 23(3), 329-345. https ://doi.org/10.1016/0001-8791(83)90046-5.

Bong, M., Cho, C., Ahn, H. S., \& Kim, H. J. (2012). Comparison of self-beliefs for predicting student motivation and achievement. The Journal of Educational Research, 105(5), 336-352. https://doi. org/10.1080/00220671.2011.627401.

Britner, S. L., \& Pajares, F. (2006). Sources of science self-efficacy beliefs of middle school students. Journal of Research in Science Teaching, 43(5), 485-499. https://doi.org/10.1002/tea.20131.

Celeux, G., \& Soromenho, G. (1996). An entropy criterion for assessing the number of clusters in a mixture model. Journal of Classification, 13(2), 195-212. https://doi.org/10.1007/BF01246098.

Chiu, M.-S. (2008). Achievements and self-concepts in a comparison of math and science: Exploring the internal/external frame of reference model across 28 countries. Educational Research and Evaluation, 14(3), 235-254. https://doi.org/10.1080/13803610802048858.

Chouinard, R., \& Roy, N. (2008). Changes in high-school students' competence beliefs, utility value and achievement goals in mathematics. British Journal of Educational Psychology, 78(1), 31-50. https://doi.org/10.1348/000709907X197993.

Chouinard, R., Karsenti, T., \& Roy, N. (2007). Relations among competence beliefs, utility value, achievement goals, and effort in mathematics. British Journal of Educational Psychology, 77(3), 501-517. https://doi.org/10.1348/000709906X133589.

Chow, A., \& Salmela-Aro, K. (2011). Task-values across subject domains: A gender comparison using a person-centered approach. International Journal of Behavioral Development, 35(3), 202-209. https://doi.org/10.1177/0165025411398184.

Cohen, J. (1988). Statistical power for the social sciences. Hillsdale, NJ: Laurence Erlbaum and Associates.

Correll, S. J. (2001). Gender and the career choice process: The role of biased self-assessments. American Journal of Sociology, 106(6), 1691-1730. https://doi.org/10.1086/321299.

DeBacker, T. K., \& Nelson, R. M. (1999). Variations on an expectancy-value model of motivation in science. Contemporary Educational Psychology, 24(2), 71-94. https://doi.org/10.1006/ ceps.1998.0984.

Dong, Y., \& Peng, C. J. (2013). Principled missing data methods for researchers. SpringerPlus, 2(1), 1-17. https://doi.org/10.1186/2193-1801-2-222.

Douglas, D., \& Attewell, P. (2017). School mathematics as gatekeeper. The Sociological Quarterly, 58(4), 648-669. https://doi.org/10.1080/00380253.2017.1354733.

Dowker, A., Sarkar, A., \& Looi, C. Y. (2016). Mathematics anxiety: What have we learned in 60 years? Frontiers in Psychology, 7, 1-16. https://doi.org/10.3389/fpsyg.2016.00508.

Eccles, J. S. (2005). Studying gender and ethnic differences in participation in math, physical science, and information technology. New Directions for Child and Adolescent Development, 110, 7-14. https://doi.org/10.1002/cd.146. 
Else-Quest, N. M., Mineo, C. C., \& Higgins, A. (2013). Math and science attitudes and achievement at the intersection of gender and ethnicity. Psychology of Women Quarterly, 37(3), 293-309. https:// doi.org/10.1177/0361684313480694.

Eshghi, A., Haughton, D., Legrand, P., Skaletsky, M., \& Woolford, S. (2011). Identifying groups: A comparison of methodologies. Journal of Data Science, 9, 271-291.

Foy, P. (2017). TIMSS 2015: User guide for the international database. Chestnut Hill, MA: Boston College.

Fredricks, J. A., \& Eccles, J. S. (2002). Children's competence and value beliefs from childhood through adolescence: Growth trajectories in two male-sex-typed domains. Developmental Psychology, 38(4), 519-533. https://doi.org/10.1037/0012-1649.38.4.519.

Frenzel, A. C., Goetz, T., Lüdtke, O., Pekrun, R., \& Sutton, R. E. (2009). Emotional transmission in the classroom: Exploring the relationship between teacher and student enjoyment. Journal of Educational Psychology, 101(3), 705-716. https://doi.org/10.1037/a0014695.

George, R. (2006). A cross-domain analysis of change in students' attitudes toward science and attitudes about the utility of science. International Journal of Science Education, 28(6), 571-589. https://doi. org/10.1080/09500690500338755.

Goldman, A. D., \& Penner, A. M. (2016). Exploring international gender differences in mathematics self-concept. International Journal of Adolescence and Youth, 21(4), 403-418. https://doi. org/10.1080/02673843.2013.847850.

Guo, J., Marsh, H. W., Parker, P. D., Morin, A. J. S., \& Yeung, A. S. (2015). Expectancy-value in mathematics, gender and socioeconomic background as predictors of achievement and aspirations: A multi-cohort study. Learning and Individual Differences, 37, 161-168. https://doi.org/10.1016/j. lindif.2015.01.008.

Guo, J., Nagengast, B., Marsh, H. W., Kelava, A., Gaspard, H., Brandt, H., et al. (2016). Probing the unique contributions of self-concept, task values, and their interactions using multiple value facets and multiple academic outcomes. AERA Open, 2(1), 1-20. https://doi.org/10.1177/2332858415 626884.

Guo, J., Marsh, H. W., Parker, P. D., Morin, A. J. S., \& Dicke, T. (2017). Extending expectancy-value theory predictions of achievement and aspirations in science: Dimensional comparison processes and expectancy-by-value interactions. Learning and Instruction, 49, 81-91. https://doi.org/10.1016/j. learninstruc.2016.12.007.

Hattie, J. (2008). Visible learning: A synthesis of over 800 meta-analyses relating to achievement. New York: Routledge.

Haughton, D., Legrad, P., \& Woolford, S. (2009). Review of three latent class cluster analysis packages: Latent GOLD, poLCA, and MCLUST. The American Statistician, 63(1), 81-91. https://doi. org/10.1198/tast.2009.0016.

Helm, F., Mueller-Kalthoff, H., Nagy, N., \& Möller, J. (2016). Dimensional comparison theory: Perceived subject similarity impacts on students' self-concepts. AERA Open, 2(2), 1-9. https://doi. org/10.1177/2332858416650624.

Holmes, K., Gore, J., Smith, M., \& Lloyd, A. (2018). An integrated analysis of school students' aspirations for STEM careers: Which student and school factors are most predictive? International Journal of Science and Mathematics Education, 16(4), 655-675. https://doi.org/10.1007/s1076 3-016-9793-z.

Jacobs, J. E., Lanza, S., Osgood, D. W., Eccles, J. S., \& Wigfield, A. (2002). Changes in children's selfcompetence and values: Gender and domain differences across grades one through twelve. Child Development, 73(2), 509-527. https://doi.org/10.1111/1467-8624.00421.

Jakobsen, J. C., Gluud, C., Wetterslev, J., \& Winkel, P. (2017). When and how should multiple imputation be used for handling missing data in randomised clinical trials - A practical guide with flowcharts. BMC Medical Research Methodology, 17(1), 1-10. https://doi.org/10.1186/s12874-017-0442-1.

Jansen, M., Schroeders, U., \& Lüdtke, O. (2014). Academic self-concept in science: Multidimensionality, relations to achievement measures, and gender differences. Learning and Individual Differences, 30, 11-21. https://doi.org/10.1016/j.lindif.2013.12.003.

Jansen, M., Schroeders, U., Lüdtke, O., \& Marsh, H. W. (2015). Contrast and assimilation effects of dimensional comparisons in five subjects: An extension of the I/E model. Journal of Educational Psychology, 107(4), 1086-1101. https://doi.org/10.1037/edu0000021.

Jung, T., \& Wickrama, K. A. S. (2008). An introduction to latent class growth analysis and growth mixture modeling. Social and Personality Psychology Compass, 2(1), 302-317. https://doi.org/10.111 1/j.1751-9004.2007.00054.x. 
Karakas, M. (2018). How to teach introductory science classes: Views of few scientists. European Journal of Education Studies, 5(6), 41-58. https://doi.org/10.5281/zenodo. 1494846.

Kennedy, J., Lyons, T., \& Quinn, F. (2014). The continuing decline of science and mathematics enrolments in Australian high schools. Teaching Science, 60(2), 34-46.

Kent, P., Jensen, R. K., \& Kongsted, A. (2014). A comparison of clustering methods for finding subgroups in MRI, SMS or clinical data: SPSS TwoStep cluster analysis, latent gold and SNOB. BMC Medical Research Methodology, 14(1), 1-14. https://doi.org/10.1186/1471-2288-14-113.

Laukaitye, I., \& Wiberg, M. (2017). Using plausible values in secondary analysis in large-scale assessments. Communications in Statistics-Theory and Methods, 46(22), 11341-11357. doi:10.1080/03 610926.2016.1267764

Lee, J., \& Stankov, L. (2018). Non-cognitive predictors of academic achievement: Evidence from TIMSS and PISA. Learning and Individual Differences, 65, 50-64. https://doi.org/10.1016/j.lindi f.2018.05.009.

Lee, B., Lawson, K. M., \& McHale, S. M. (2015). Longitudinal associations between gender-typed skills and interests and their links to occupational outcomes. Journal of Vocational Behavior, 88, 121130. https://doi.org/10.1016/j.jvb.2015.02.011.

Lin, L., Lee, T., \& Snyder, L. A. (2018). Math self-efficacy and STEM intentions: A person- centered approach. Frontiers in Psychology, 9, 1-13. https://doi.org/10.3389/fpsyg.2018.02033.

Liou, P.-Y. (2017). Profiles of adolescents' motivational beliefs in science learning and science achievement in 26 countries: Results from TIMSS 2011 data. International Journal of Educational Research, 81, 83-96. https://doi.org/10.1016/j.ijer.2016.11.006.

Lo, Y., Mendell, N., \& Rubin, D. (2001). Testing the number of components in a normal mixture. Biometrika, 88(1), 767-778. https://doi.org/10.1093/biomet/88.3.767.

Louis, R. A., \& Mistele, J. M. (2012). The differences in scores and self-efficacy by student gender in mathematics and science. International Journal of Science and Mathematics Education, 10(5), 1163-1190. https://doi.org/10.1007/s10763-011-9325-9.

Marsh, H. W. (1986). Verbal and math self-concepts: An internal/external frame of reference model. American Educational Research Journal, 23(1), 129-149. https://doi.org/10.3102/0002831202 3001129.

Marsh, H. W., \& Craven, R. G. (2006). Reciprocal effects of self-concept and performance from a multidimensional perspective: Beyond seductive pleasure and unidimensional perspectives. Perspectives on Psychological Science, 1(2), 133-163. https://doi.org/10.1111/j.1745-6916.2006.00010.x.

Marsh, H. W., \& Martin, A. J. (2011). Academic self-concept and academic achievement: Relations and causal ordering. British Journal of Educational Psychology, 81(1), 59-77. https://doi. org/10.1348/000709910X503501.

Marsh, H. W., Seaton, M., Trautwein, U., Lüdtke, O., Hau, K. T., O’Mara, A. J., et al. (2008). The bigfish-little-pond-effect stands up to critical scrutiny: Implications for theory, methodology, and future research. Educational Psychology Review, 20(3), 319-350. https://doi.org/10.1007/s1064 8-008-9075-6.

Marsh, H. W., Möller, J., Parker, P., Xu, M. K., Nagengast, B., \& Pekrun, R. (2015). Internal/external frame of reference model. In J. D. Wright (Ed.), International encyclopedia of the social \& behavioral sciences (2nd ed., pp. 425-432). Oxford, United Kingdom: Elsevier.

Martin, M. O., Mullis, I. V. S., Hooper, M., Yin, L., Foy, P., \& Palazzo, L. (2016). Creating and interpreting the TIMSS 2015 context questionnaire scales. In M. O. Martin, I. V. S. Mullis, \& M. Hooper (Eds.), Methods and procedures in TIMSS 2015 (pp. 558-869). Chestnut Hill, MA: Boston College.

Mau, W.-C. (2003). Factors that influence persistence in science and engineering career aspirations. The Career Development Quarterly, 51(3), 234-243. https://doi.org/10.1002/j.2161-0045.2003.tb006 04.x.

Michaelides, M. P., Brown, G. T. L., Eklöf, H., \& Papanastasiou, E. C. (2019). Introduction to motivational profiles in TIMSS mathematics. In M. P. Michaelides, G. T. L. Brown, H. Eklöf, \& E. C. Papanastasiou (Eds.), Motivational profiles in TIMSS mathematics: Exploring student clusters across countries and time (pp. 1-7). Cham, Switzerland: Springer.

Nagengast, B., \& Marsh, H. W. (2012). Big fish in little ponds aspire more: Mediation and cross-cultural generalizability of school-average ability effects on self-concept and career aspirations in science. Journal of Educational Psychology, 104(4), 1033-1053. https://doi.org/10.1037/a0027697.

Nagy, G., Garrett, J., Trautwein, U., Cortina, K. S., Baumert, J., \& Eccles, J. S. (2008). Gendered high school course selection as a precursor of gendered occupational careers: The mediating role of self-concept and intrinsic value. In H. M. G. Watt \& J. S. Eccles (Eds.), Gender and 
occupational outcomes: Longitudinal assessments of individual, social, and cultural influences (pp. 115-143). Washington, DC: American Psychological Association.

Nagy, G., Watt, H. M. G., Eccles, J. S., Trautwein, U., Lüdtke, O., \& Baumert, J. (2010). The development of students' mathematics self-concept in relation to gender: Different countries, different trajectories? Journal of Research on Adolescence, 20(2), 482-506. https://doi.org/10.111 1/j.1532-7795.2010.00644.x.

Nyland, K. L., Asparouhov, T., \& Muthén, B. O. (2007). Deciding on the number of classes in latent class analysis and growth mixture modelling: A Monte Carlo simulation study. Structural Equation Modeling: A Multidisciplinary Journal, 14(4), 535-569. https://doi.org/10.1080/10705 510701575396.

Plenty, S., \& Heubeck, B. G. (2013). A multidimensional analysis of changes in mathematics motivation and engagement during high school. Educational Psychology, 33(1), 14-30. https://doi. org/10.1080/01443410.2012.740199.

Potvin, P., Hasni, A., Sy, O., \& Riopel, M. (2018). Two crucial years of science and technology schooling: A longitudinal study of the major influences on and interactions between self-concept, interest, and the intention to pursue science and technology. Research in Science Education. https://doi.org/10.1007/s11165-018-9751-6.

Riegle-Crumb, C., Moore, C., \& Ramos-Wada, A. (2011). Who wants to have a career in science or math? Exploring adolescents' future aspirations by gender and race/ethnicity. Science Education, 95(3), 458-476. https://doi.org/10.1002/sce.20431.

Sass, S., \& Kampa, N. (2019). Self-concept profiles in lower secondary level-An explanation for gender differences in science course selection? Frontiers in Psychology, 10, 1-14. https://doi. org/10.3389/fpsyg.2019.00836.

Sax, L. J., Kanny, M. A., Riggers-Piehl, T. A., Whang, H., \& Paulson, L. N. (2015). "But I'm not good at math": The changing salience of mathematical self-concept in shaping women's and men's STEM aspirations. Research in Higher Education, 56(8), 813-842. https://doi.org/10.1007/s1116 2-015-9375-X.

Schreiber JB, Pekarik AJ (2014) Technical note: Using latent class analysis versus k-means or hierarchical clustering to understand museum visitors. Curator: The Museum Journal 57(1), 45-59. DOI: $10.1111 /$ cura.12050.

Shapka, J. D., Domene, J. F., \& Keating, D. P. (2006). Trajectories of career aspirations through adolescence and young adulthood: Early math achievement as a critical filter. Educational Research and Evaluation, 12(4), 347-358. https://doi.org/10.1080/13803610600765752.

Sikora, J., \& Pokropek, A. (2012). Gender segregation of adolescent science career plans in 50 countries. Science Education, 96(2), 234-264. https://doi.org/10.1002/sce.20479.

Skaalvik, S., \& Skaalvik, E. M. (2004). Gender differences in math and verbal self-concept, performance expectations, and motivation. Sex Roles, 50(3/4), 241-252. https://doi.org/10.1023/ B:SERS.0000015555.40976.e6.

Stake, J. E. (2006). The critical mediating role of social encouragement for science motivation and confidence among high school girls and boys. Journal of Applied Social Psychology, 36(4), 1017-1045. https://doi.org/10.1111/j.0021-9029.2006.00053.x.

Stankov, L. (2013). Noncognitive predictors of intelligence and academic achievement: An important role of confidence. Personality and Individual Differences, 55(7), 727-732. https://doi. org/10.1016/j.paid.2013.07.006.

Stankov, L., \& Lee, J. (2017). Self-beliefs: Strong correlates of mathematics achievement and intelligence. Intelligence, 61, 11-16. https://doi.org/10.1016/j.intell.2016.12.001.

Sterba, S. K., \& Bauer, D. J. (2010). Matching method with theory in person-oriented developmental psychopathology research. Development and Psychopathology, 22(2), 239-254. https://doi. org/10.1017/S0954579410000015.

Thomson, S., Wernert, N., O'Grady, E., \& Rodrigues, S. (2017). TIMSS 2015: Reporting Australia's results. Melbourne, Australia: Australian Council for Educational Research.

Van Montfort, E., Denollet, J., Vermut, J. K., Widdershoven, J., \& Kupper, N. (2017). The tense, the hostile and the distressed: Multidimensional psychosocial risk profiles based on the ESC interview in coronary artery disease patients- the THORESCI study. General Hospital Psychiatry, 47, 103-111. https://doi.org/10.1016/j.genhosppsych.2017.05.006.

Von Davier, M., Gonzalez, E., \& Mislevy, R. J. (2009). What are plausible values and why are they useful? IERI Monograph Series, 2, 9-36. 
Wang, M.-T. (2012). Educational and career interests in math: A longitudinal examination of the links between classroom environment, motivational beliefs, and interests. Developmental Psychology, 48(6), 1643-1657. https://doi.org/10.1037/a0027247.

Wang, M.-T., \& Degol, J. (2013). Motivational pathways to STEM career choices: Using expectancyvalue perspective to understand individual and gender differences in STEM fields. Developmental Review, 33(4), 304-340. https://doi.org/10.1016/j.dr.2013.08.001.

Watt, H. M. G. (2004). Development of adolescents' self-perceptions, values, and task perceptions according to gender and domain in 7th- through 11th-grade Australian students. Child Development, 75(5), 1556-1574. https://doi.org/10.1111/j.1467-8624.2004.00757.x.

Watt, H. M. G. (2006). The role of motivation in gendered educational and occupational trajectories related to maths. Educational Research and Evaluation, 12(4), 305-322. https://doi. org/10.1080/13803610600765562.

Watt, H. M. G., Shapka, J. D., Morris, Z. A., Durik, A. M., Keating, D. P., \& Eccles, J. S. (2012). Gendered motivational processes affecting high school mathematics participation, educational aspirations, and career plans: A comparison of samples from Australia, Canada, and the United States. Developmental Psychology, 48(6), 1594-1611. https://doi.org/10.1037/a0027838.

Watt, H. M. G., Hyde, J. S., Petersen, J., Morris, Z. A., Rozek, C. S., \& Harackiewicz, J. M. (2017). Mathematics - a critical filter for STEM-related career choices? A longitudinal examination among Australian and US adolescents. Sex Roles, 77(3), 254-271. https://doi.org/10.1007/s11199-016-0711-1.

Watt, H. M. G., Bucich, M., \& Dacosta, L. (2019). Adolescents' motivational profiles in mathematics and science: Associations with achievement striving, career aspirations and psychological wellbeing. Frontiers in Psychology, 10, 1-23. https://doi.org/10.3389/fpsyg.2019.00990.

Wigfield, A., \& Eccles, J. S. (2000). Expectancy-value theory of achievement motivation. Contemporary Educational Psychology, 25(1), 68-81. https://doi.org/10.1006/ceps.1999.1015.

Wigfield, A., Eccles, J. S., Fredricks, J., Simpkins, S., Roeser, R. W., \& Schiefele, U. (2015). Development of achievement motivation and engagement. In M. E. Lamb \& R. M. Lerner (Eds.), Handbook of child psychology and developmental science: Socioemotional processes (pp. 657-700). Hoboken, NJ: Wiley.

Wilkins, J. L. M. (2004). Mathematics and science self-concept: An international investigation. The Journal of Experimental Education, 72(4), 331-346. https://doi.org/10.3200/JEXE.72.4.331-346.

Publisher's Note Springer Nature remains neutral with regard to jurisdictional claims in published maps and institutional affiliations.

Nathan Berger, PhD is Postdoctoral Research Fellow in STEM Education in the Centre for Educational Research at Western Sydney University. He has degrees in information technology, secondary teaching, and educational research from the University of Newcastle, Australia. Nathan's teaching and research interests include educational psychology, with a focus on young people's aspirations and motivations, and secondary STEM education.

Erin Mackenzie, $\mathrm{PhD}$ is a Lecturer in the School of Education and a researcher in the Centre for Educational Research at Western Sydney University. She has experience teaching in secondary schools and university settings, and lectures in educational psychology, secondary science pedagogy, and STEM education. Erin's research interests include adolescent online interactions, coping, and the role of psychological and social factors in adolescent girls' participation in STEM.

Kathryn Holmes, PhD is a Professor of Education (Science, Technology, Mathematics) in the School of Education. She is the Director of the Centre for Educational Research and has broad research interests in mathematics and STEM education, teaching with technology, student wellbeing and factors impacting on educational equity. She has taught mathematics and science in secondary schools, and has developed online courses in mathematics and STEM education to support teacher professional development. 